\title{
CINÉTICA DA DEGRADAÇÃO DE COMPOSTOS ORGÂNICOS NO SOLO
}

\author{
DANIELA SOARES ALVES CALDEIRA \\ Engenheiro Agrônomo
}

Orientador: Prof. Dr. ARNALDO ANTONIO RODELLA

\begin{abstract}
Dissertação apresentada à Escola Superior de Agricultura "Luiz de Queiroz", Universidade de São Paulo, para obtenção do título de Mestre em Agronomia, Área de Concentração : Solos e Nutrição de Plantas.
\end{abstract}

PIRACICABA

Estado de São Paulo - Brasil

Setembro - 1997 


\section{Dados Internacionais de Catalogação na Publicação (CIP) DIVISÃO DE BIBLIOTECA E DOCUMENTAÇÃO - Campus "Luiz de Oueiroz"/USP}

Caldeira, Daniela Soares Alves

Cinética da degradaçāo de compostos orgânicos no solo / Daniela Soares Alves Caldeira. - - Piracicaba, 1997.

$68 \mathrm{p}$.

Dissertaçāo (mestrado) - - Escola Superior de Agricultura Luiz de Queiroz, 1997. Bibliografia.

1. Composto orgânico 2. Decomposiçāo 3. Efeito da temperatura 4. Latossolo vermelho-amarelo 5. Residuo orgânico I. Título 


\section{CINÉTICA DA DEGRADAÇÃO DE COMPOSTOS ORGÂNICOS NO SOLO}

DANIELA SOARES ALVES CALDEIRA

Aprovada em: 30.10 .1997

Comissão julgadora:

Prof. Dr. Arnaldo Antonio Rodella ESALQ/USP

Prof. Dr. Márcio Rodrigues Lambais ESALQ/USP

Prof. Dr. Augusto Ferreira da Eira FCA/UNESP

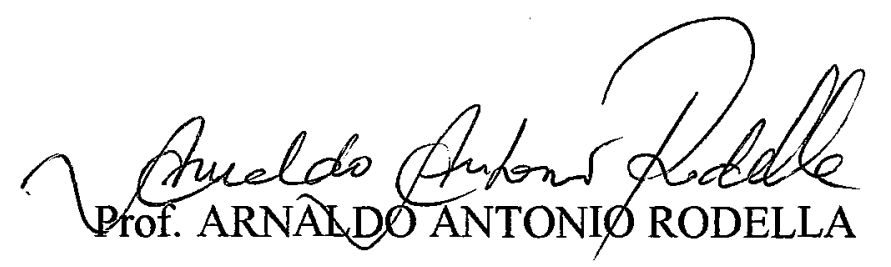

Orientador 


\section{OFEREÇO}

À minha mãe Maria Lúcia e ao meu pai Tiassu,

pela confiança, dedicação e apoio em todos os meus dias.

Aos meus queridos avós Lúcio e Felícia,

por tudo que fizeram e pela falta que fazem.

À Dedé, Frederico e Raquelzinha, Ao meu gatinho Luís Fernando, DEDICO. 


\section{AGRADECIMENTOS}

Ao meu Orientador e amigo, Prof. Dr. Arnaldo Antonio Rodella, pela presença, apoio, paciência e dedicação na orientação deste trabalho.

À CAPES e à FAPESP, pela concessão das Bolsas de Estudo.

À Banca Examinadora, pelas sugestões apresentadas.

À bibliotecária Eliana, pela correção das Referências Bibliográficas.

À Giovana, pela ajuda nos momentos difíceis.

Aos colegas do Departamento de Química Analítica/ESALQ: Angélica, Armelinda, Christian, Carlos, Lenita, Jana e Rita, pela colaboração e convívio.

Aos colegas da pós-graduação: Edna, Marcelo, Ana Rosa, Úrsula, Tadeu, Fátima, Adriana, Fábios, Fernando, Marchiori, Adônis, M urbach́, Érika, Marcão, César, João e Reinaldo, pela convivência agradável em Piracicaba.

Ao Prof. Dr. João Antônio Galbiatti, por toda a ajuda e incentivo para chegar até aqui.

Aos queridos Carlão, Marisa, Drica, Maria José, Kaké e Ana, pelo apoio, motivação e bem querer.

À minha família, por estar sempre ao meu lado, me encorajando e não permitindo que eu desanime jamais.

A DEUS, por fazer dos meus dias sempre uma conquista. 


\section{SUMÁRIO}

Página

RESUMO ......................................................................... vii

SUMMARY

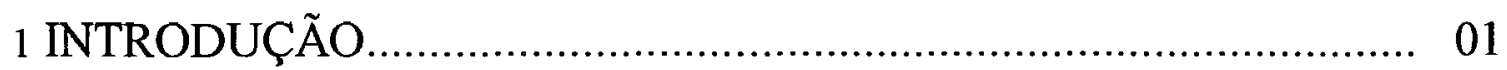

2 REVISÃO DE LITERATURA.............................................. 04

2.1 Adição de materiais orgânicos ao solo........................................ 05

2.2 Decomposição dos materiais orgânicos no solo........................... 06

2.2.1 Fatores que afetam a velocidade de decomposição............... 07

2.2.2 Cinética da degradação de compostos orgânicos................. 09

2.2.2.1 O modelo de cinética de primeira ordem.................. 11

2.3 Métodos utilizados para estimar a decomposição dos materiais orgânicos............................................................. 15

2.3.1 A decomposição avaliada através da respirometria..................16

3 MATERIAL E MÉTODOS ...................................................... 20

3.1 Caracterização dos materiais utilizados................................... 20

3.1.1 Determinação da natureza orgânica de um material............... 24

3.2 Caracterização dos experimentos.............................................. 26

3.2.1 Experimento1.Decomposição de diferentes compostos orgânicos no solo...................................................... 26

3.2.2 Experimento2. Efeito da temperatura na decomposição dos compostos orgânicos no solo. 
3.2.3 Experimento 3. Decomposição conjunta de compostos orgânicos incubados no solo.......................................... 30

3.2.4 Experimento 4. Decomposição de resíduos orgânicos no solo.

4 RESULTADOS E DISCUSSÃO 33

4.1 Experimento 1. Decomposição de diferentes compostos orgânicos no solo.

4.2 Experimento2. Efeito da temperatura na decomposição dos compostos orgânicos no solo.. 40

4.3 Experimento 3. Decomposição conjunta de compostos orgânicos incubados no solo 48

4.4 Experimento 4. Decomposição de residuos orgânicos no solo. 54

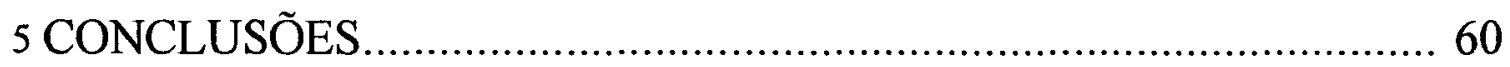

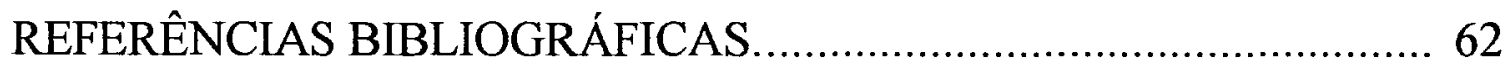




\title{
CINÉTICA DA DEGRADAÇÃO DE COMPOSTOS ORGÂNICOS NO SOLO
}

\author{
Autora: DANIELA SOARES ALVES CALDEIRA \\ Orientador: Prof. Dr. ARNALDO ANTONIO RODELLA
}

\section{RESUMO}

Estudos de degradação de materiais orgânicos no solo têm sido explorados, com a finalidade de se conhecer a dinâmica desse processo. Esse enfoque pode ser considerado sob dois pontos de vista principais: a adição de materiais orgânicos ao solo visando aumentar o teor de carbono, ou, ao contrário, o uso do solo como depurador de resíduos agroindustriais e urbanos.

O objetivo principal do presente estudo foi avaliar a aplicação do modelo de cinética de primeira ordem a resultados de quatro ensaios de incubação conduzidos em casa de vegetação e estufa incubadora. Foram estudados compostos orgânicos puros, isoladamente ou em mistura, resíduos vegetais, industriais e urbanos, sendo o acompanhamento de sua degradação 
efetuado por meio de medidas do $\mathrm{CO}_{2}$ liberado do solo, através de respirômetros de retenção passiva.

Foi possível comparar a degradação de diversos compostos orgânicos através de suas constantes de velocidade de primeira ordem, destacando as similaridades e diferenças de comportamento. $O$ efeito da temperatura sobre a cinética de degradação pôde também ser caracterizado através dos parâmetros cinéticos .

$\mathrm{O}$ modelo de cinética em duas fases, cada uma correspondente a diferentes frações de carbono em degradação, foi eficiente para avaliar tratamentos nos quais diferentes compostos foram misturados. No estudo envolvendo decomposição de resíduos orgânicos industriais e urbanos detectou-se um comportamento diferenciado da degradação da matéria orgânica nativa do solo sob a influência do material orgânico adicionado.

$\mathrm{O}$ estudo evidenciou que, de maneira geral, o modelo de cinética de primeira ordem foi adequado para avaliar a degradação de compostos orgânicos no solo, pois coeficientes de determinação de elevada magnitude foram obtidos. As constantes de velocidade de primeira ordem puderam ser empregadas para caracterizar adequadamente o comportamento dos materiais orgânicos no solo estudado. 


\title{
KINETICS OF DECOMPOSITION OF ORGANIC COMPOUNDS ADDED TO THE SOIL
}

\author{
Author: DANIELA SOARES ALVES CALDEIRA \\ Adviser: Prof. Dr. ARNALDO ANTONIO RODELLA
}

\section{SUMMARY}

Studies concerning the decomposition of organic materials in soils are generally useful to evaluate the dynamics of this process. Basically, two points may be emphasized: soil organic matter increasing upon addition of organic material or, in contrast, using soil as a mean of industrial or domestic organic waste depuration.

In order to study the kinetics of degradation of organic compounds in soil, four pot experiments were carried out both in greenhouse and laboratory to compare decomposition rates of pure chemicals, plant and waste materials. Total $\mathrm{CO}_{2}$ evolved during the degradation of pure organic compounds in a Red Yellow Latossol, quantified by a conductometric method, were fitted to a first order kinetics model.

The sequence of decreasing degradation rates were: sucrose, soyabean protein, glycerin, pectin, citric acid, corn starch, tannin, cellulose, soybean oil, agar, humic acid and lignin. The temperature effect was 
dependent on the nature of the organic compound. Sucrose was fastest decomposed, followed by tannin and pectin. Generally, first order kinetics was suitable to evaluate the decomposition of organic compounds in soils with the exception of the first stages of pectin decomposition. First order constants were successfully used to consider the process of degradation of organic compounds in the studied soil.

A kinetic model comprising two pools of organic compounds, each one with its specific degradation rate, was useful to evaluate the behavior of mixed organic materials. When industrial and domestic wastes were incorporated to the soil, the kinetics of the native soil organic matter decomposition seemed to be affected. 


\section{INTRODUÇÃO}

A matéria orgânica é um importante constituinte do solo e é formada por restos vegetais frescos, fração estabilizada resistente à decomposição, denominada húmus e pelos microrganismos que nele vivem. É encontrada em diferentes estágios de decomposição; o conteúdo e a composição da matéria orgânica são consequiências de fatores diversos, tais como: o tipo de vegetação, a topografia e o clima, entre outros.

Sua dinâmica no solo tem papel fundamental nos ecossistemas naturais e na agricultura, onde compostos orgânicos chegam a atuar como reservatório temporário de nutrientes, o que resulta em aumento de eficiência na utilização dos nutrientes do solo e dos fertilizantes empregados.

Tem-se que, o teor de matéria orgânica no solo é resultado líquido de processos de adição e decomposição de materiais adicionados, ou seja, do balanço entre a velocidade de decomposição microbiana e a velocidade de adição de resíduos orgânicos frescos.

No solo, o material orgânico é oxidado pelos microrganismos, que degradam moléculas orgânicas complexas a compostos simples, os quais podem ser assimilados como fonte de carbono para obtenção de energia. A atividade microbiana é afetada pelas condições de umidade, aeração, 
temperatura e $\mathrm{pH}$, além do indispensável suprimento de nutrientes e de fontes energéticas do solo.

Em condições não limitantes, um dos produtos finais da oxidação do carbono orgânico é o $\mathrm{CO}_{2}$. Essa atividade, denominada respiratória, pode ser avaliada através da determinação da quantidade de $\mathrm{CO}_{2}$ produzida por uma determinada quantidade de solo, ao longo de um período de tempo conhecido, em condições controladas ou no campo.

A decomposição de um resíduo orgânico no solo pode então ser avaliada parcialmente através desse $\mathrm{CO}_{2}$ liberado durante o processo e determinada através da respirometria, com a obtenção de curvas de velocidade de decomposição de diversos materiais.

Deve-se lembrar que todos estes materiais estão se decompondo simultaneamente, quando tecidos vegetais são adicionados ao solo; entretanto, o grau em que esta decomposição ocorre é que se torna dependente do material. Celulose e hemicelulose são considerados compostos orgânicos de moderada ou intermediária resistência à decomposição. A lignina é tida como resistente, enquanto os açúcares simples, ou carboidratos não polimerizados, bem como as proteínas são tidos como fontes de carbono mais disponíveis aos microrganismos.

Assim esses materiais orgânicos adicionados ao solo podem contribuir como fonte de nutrientes para as plantas, além de melhorar as características químicas, físicas e biológicas do solo.

Para os diferentes experimentos conduzidos o objetivo específico foi estudar a adequação do modelo de cinética de primeira ordem 
na degradação de diversos materiais incorporados em um Latossolo Vermelho Amarelo, fase arenosa, sob os seguintes pontos de vista:

- decomposição de diferentes tipos de compostos orgânicos no solo.

- efeito da temperatura na decomposição dos compostos orgânicos no solo.

- decomposição conjunta de compostos orgânicos incubados no solo

•decomposição de resíduos orgânicos no solo. 


\section{REVISÃO DE LITERATURA}

$\mathrm{O}$ carbono mineral na forma de $\mathrm{CO}_{2}$ é fixado principalmente através da fotossíntese pelas plantas verdes na forma de carboidratos, lignina, proteínas, lipídeos e outros compostos orgânicos. Com a senescência e morte dos órgãos aéreos e raízes das plantas, esse carbono orgânico é colocado em contato com o solo e, com o passar do tempo, é decomposto pelos microrganismos do solo.

A matéria orgânica do solo é constituída basicamente de resíduos frescos de plantas, animais e microrganismos que, ao sofrerem decomposição, perdem de maneira rápida sua identidade química e como conseqüência, liberam nutrientes. Há também a fração recalcitrante, formada por compostos resistentes à decomposição e que promove melhorias fisicas e químicas de um solo: o húmus.

Quando um material orgânico é adicionado ao solo, os microrganismos heterotróficos ali presentes promovem, através de reações de oxidação, a decomposição deste material. Nessas reações de oxidação, parte do carbono do substrato é utilizado para suas funções celulares e parte é perdida na forma de $\mathrm{CO}_{2}$. Uma das técnicas para estimar a velocidade de decomposição de materiais adicionados ao solo envolve justamente a medida 
desse $\mathrm{CO}_{2}$ liberado (Waskman, 1963; Alexander,1967; Parr, 1975; Eira \& Paccola, 1980; Almeida ,1983; Siqueira, 1983).

A velocidade e eficácia na decomposição do material orgânico dependem de uma série de fatores relacionados com a composição química e quantidade do substrato e com as características físico-químicas do solo, incluindo as condições climáticas (Alexander, 1967; Parr, 1975).

\subsection{Adição de materiais orgânicos ao solo}

A incorporação ao solo de resíduos orgânicos, de origem animal ou vegetal, como meio de manter e aumentar a fertilidade do solo, remonta da antigüidade e constitui técnica eficaz contra sua degradação. A decomposição desses materiais garante um bom desenvolvimento aos vegetais, pelas melhorias que proporciona.

A principal fonte de compostos orgânicos para o solo é de origem vegetal e se caracteriza pela natureza variada e complexa, mas é dominada pelos carboidratos: celulose, hemicelulose, amido, substâncias pécticas, açúcares; pela lignina; pelos compostos nitrogenados, como proteínas e aminoácidos; além de outros constituintes como ceras, graxas, ácidos orgânicos, pigmentos e taninos (Siqueira, 1983).

Os adubos orgânicos também são amplamente utilizados e neles se inclui uma variedade de materiais cuja composição e resistência à decomposição no solo, variam acentuadamente (Kiehl, 1985).

A geração de resíduos no Brasil tem mostrado valores expressivos, representando um problema econômico e um sério prob稀ma ambiental, 
fazendo com que se considere seriamente a sua utilização na cadeia produtiva (Souza, 1997). A mineralização da matéria orgânica adicionada ao solo pode ser utilizada como um processo de diminuição da carga orgânica desses resíduos agrícolas ou industriais. Dependendo da natureza do material, podem contribuir ainda para a melhoria da fertilidade do solo.

Dentre os resíduos orgânicos mais importantes pode ser citada a vinhaça, que varia muito em composição, mas de modo geral possui elevados teores de materiais carbonáceos. Quando da assimilação do carbono desses materiais, ocorre uma concomitante assimilação de outros elementos também importantes para o crescimento microbiano, tais como: o nitrogênio, fósforo, potássio e enxofre, podendo ou não estar presentes no resíduo, em níveis satisfatórios. A assimilação de tais nutrientes adicionais poderá ter uma grande significação prática porque, se o resíduo não os contiver em teores satisfatórios para a decomposição microbiana, ocorrerá uma imobilização dos nutrientes da solução do solo, reduzindo assim, a sua disponibilidade para as plantas (Alexander, 1967).

\subsection{Decomposição dos materiais orgânicos no solo}

Os compostos orgânicos variam enormemente em sua resistência à decomposição. Podem ser relacionados de acordo com sua facilidade de decomposição: açúcares, amido e proteínas são decompostos rapidamente, seguidos pelas hemicelulose e celulose; enquanto a lignina, as gorduras e as ceras são decompostos muito lentamente (Brady,1989). Como exemplo, 
pode-se citar que as plantas jovens contém porcentagens relativamente altas de substâncias que se decompõem prontamente, conforme Martins (1987).

Vanlawe et al. (1994) estudaram o fracionamento da matéria orgânica de folhas de milho desenvolvidas em câmaras de crescimento, sob atmosfera contendo ${ }^{14} \mathrm{CO}_{2}$. Visando separar frações de diferentes graus de resistência à decomposição, obtiveram as frações: solúvel, correspondendo a $48 \%$ da matéria seca, constituída essencialmente por carboidratos não polimerizados e proteínas, considerada prontamente decomponível; resistente, composta de hemicelulose e celulose (46,7\% da matéria seca), considerada resistente à decomposição e uma fração referente à lignina e compostos relacionados, definida como recalcitrante, correspondente à apenas $1 \%$ da matéria seca. Os autores justificam a baixa proporção de lignina pelo fato de as folhas serem jovens.

A lignina, conforme Cardoso et al. (1992), constitui a fração mais resistente à degradação e de acordo com Smolander et al. (1996), sobre a decomposição de acículas de pinheiro, a lignina do albedo se decompôs mais rapidamente que a lignina do pinheiro, mostrando que a decomposição desta varia com a espécie vegetal considerada.

\subsubsection{Fatores que afetam a velocidade de decomposição}

A velocidade com que um resíduo é consumido pela microbiota do solo depende da sua constituição química e das condições ambientais. Dentre os fatores do substrato citam-se a composição química, sua relação $\mathrm{C} / \mathrm{N}$, seu conteúdo em lignina, tamanho ou estado de subdivisão das 
partículas e natureza da microbiota. Entre os fatores do solo podem ser incluídos: temperatura, pressão parcial de oxigênio, umidade, $\mathrm{pH}$, disponibilidade de nutrientes, textura, estrutura e mineralogia do solo (Evans,1973; Parr, 1975).

Quanto ao tipo de material adicionado, Minhoni et al. (1990) concluíram que a velocidade de decomposição reflete o grau de biodegradabilidade. Materiais mais simples, como a glicose e vinhaça, são mais rápida e facilmente decompostos que palha de soja ou bagaço de cana.

A relação $\mathrm{C} / \mathrm{N}$ (carbono/nitrogênio) é um fator que influi muito na velocidade de decomposição dos resíduos e essa relação é bastante variável. Resíduos de leguminosas que possuem relação $\mathrm{C} / \mathrm{N}$ em torno de 20 são de fácil decomposição, enquanto que as palhas de alguns cereais com relação $\mathrm{C} / \mathrm{N}$ em torno de 200 exigem um período muito maior para a sua completa decomposição (Martins,1987). Porém, durante a decomposição, essa relação $\mathrm{C} / \mathrm{N}$ diminui (Alexander, 1967) e isso ocorre porque, no metabolismo microbiano parte do carbono é perdido na forma de $\mathrm{CO}_{2}$.

Outros elementos, principalmente o fósforo e o enxofre, além de microelementos, quando em quantidades insuficientes, tornam-se fatores limitantes para a biodegradação de compostos orgânicos (Alexander, 1961; Waksman, 1963).

Outro fator condicionador da decomposição é a temperatura. Alexander (1967) relatou que a mineralização do carbono é mais lenta a baixas temperaturas e que o aquecimento está associado com um maior desprendimento de $\mathrm{CO}_{2}$. Parr (1975) considerou a faixa de $30-35^{\circ} \mathrm{C}$ como 
sendo a de máxima velocidade de decomposição de materiais orgânicos de modo geral.

Segundo Waksman (1963), a umidade requerida para a máxima produção de $\mathrm{CO}_{2}$ está entre 53 e $71 \%$ e, sob condições aeróbias, a decomposição dos principais constituintes orgânicos é mais intensa do que em condições anaeróbias. Parr (1975) considerou que sob condições mais úmidas, a matéria orgânica decompõe-se mais lentamente, em virtude do inadequado fornecimento de $\mathrm{O}_{2}$. Nessas condições, o metabolismo microbiano torna-se anaeróbico e/ou fermentativo, havendo diminuição da liberação de $\mathrm{CO}_{2}$ em decorrência da produção de outros compostos finais ricos em carbono e energia, tais como metano, ácidos orgânicos e álcoois (Ponnamperuma, 1972).

Em relação aos demais fatores condicionadores da decomposição, Terry et al. (1979) verificaram que a textura, $\mathrm{pH}$ e mesmo a umidade, tiveram pouco efeito na velocidade de decomposição de lodo de esgoto em solo. Porém, quanto ao modo de aplicação e à temperatura, obtiveram uma maior decomposição quando a aplicação era superficial ou quando a temperatura era de $30^{\circ} \mathrm{C}$, em comparação à incorporação ou quando a temperatura era $21^{\circ} \mathrm{C}$.

\subsubsection{Cinética da degradação de compostos orgânicos}

O conhecimento da cinética é importante no estudo da degradação da matéria orgânica no solo, inclusive para avaliar a persistência da maioria dos poluentes orgânicos. Nesse aspecto, Morrill et al. (1982) consideraram o 
emprego de modelos cinéticos à degradação de pesticidas no solo, destacando as limitações decorrentes da presença do produto proveniente de aplicações anteriores, no ajuste de modelos exponenciais, como o de primeira ordem.

Alexander \& Scow (1989) comentaram que quando a degradação de um composto químico começa, a quantidade deste diminui em função do tempo e a forma desta curva será função da natureza do composto em questão, de sua concentração, dos organismos responsáveis e uma variedade de fatores ambientais. O solo é um ambiente complexo do ponto de vista químico e físico e a composição da comunidade microbiana é bastante heterogênea, o que torna dificil extrapolar para o solo resultados de cinética de degradação obtidos em culturas puras de microrganismos, sob condições controladas. As principais razões que contribuem para isso são:

-presença de outras moléculas orgânicas que podem ser metabolizadas pelas espécies biodegradantes, podendo reprimir ou acelerar o consumo do composto testado;

-moléculas orgânicas podem encontrar-se sorvidas à argila ou constituintes húmicos, de modo a diferenciar a cinética deste substrato em relação ao mesmo composto livre em solução;

-muitos substratos como compostos químicos sintéticos e poluentes podem ser insolúveis em água e a cinética de sua degradação pode ser totalmente diferente dos compostos em fase aquosa;

-muitos compostos orgânicos somente se degradam após um período de aclimatação. 
Um parâmetro bastante utilizado para avaliar a degradação de diferentes materiais orgânicos e compará-los é a meia-vida, definido como o período de tempo necessário para que metade da quantidade de material inicialmente considerada se degrade. Jenkinson \& Rayner (1977) estabeleceram meia-vida de 0,165 anos para os açúcares, proteínas e polímeros de carboidratos; meia-vida de 2,31 anos para a celulose e lignina, meia-vida de 49,5 anos para a matéria orgânica fisicamente estabilizada e meia-vida de 1980 anos para as substâncias húmicas.

Paul (1984), citando dados experimentais de Voroney com carbono marcado, determinou a degradação do carbono orgânico da glicose incorporada ao solo, através de equações. A seguinte proporção foi obtida: $29 \%$ foi degradado rapidamente, com meia-vida de 2 dias, enquanto uma fração intermediária, $41 \%$ do total adicionado, se degradou com meia-vida de 30 dias, correspondendo à decomposição de biomassa microbiana e de seus metabólitos. Os 30\% restantes sofreram decomposição lenta, meia-vida de 3450 dias, correspondendo a uma fração altamente estabilizada em que o carbono da glicose tinha sido incorporado.

\subsubsection{O modelo de cinética de primeira ordem}

Com a finalidade de melhor entender as transformações que sofre a matéria orgânica no solo, Rodella (1996) relatou fazer-se necessário o estudo da cinética das reações de decomposição de substratos orgânicos. Para tanto, pode-se formular modelos matemáticos. Um bastante simples é o 
modelo de cinética de primeira ordem, largamente utilizado nos estudos de degradação da matéria orgânica (Jenkinson \& Rayner, 1977).

Esse modelo baseia-se, de acordo com Lathan (1974), no princípio de que a velocidade de decomposição de um substrato, em um determinado instante, é diretamente proporcional à quantidade de substrato presente nesse mesmo instante. Desde que a quantidade de substrato é máxima no início do processo e diminui com o tempo, a velocidade de decomposição é decrescente. Em termos matemáticos o princípio citado é expresso pela equação diferencial:

$$
-\frac{\mathrm{d} \mathrm{C}_{\mathrm{t}}}{\mathrm{dt}}=\mathrm{k}\left(\mathrm{C}_{\mathrm{i}}-\mathrm{C}_{\mathrm{t}}\right)
$$

na qual $C_{i}$ é a quantidade inicial de carbono passível de ser decomposto microbiologicamente em $\mathrm{CO}_{2}$ e $\mathrm{H}_{2} \mathrm{O}$ e $\mathrm{C}_{\mathrm{t}}$ é a quantidade de carbono decomposta no tempo $t$.

A integração da citada equação diferencial leva à expressão do modelo de cinética de primeira ordem na forma integrada

$$
\mathrm{C}_{\mathrm{t}}=\mathrm{C}_{\mathrm{i}}\left(1-\mathrm{e}^{-\mathrm{k} . \mathrm{t}}\right)
$$

A quantidade de carbono remanescente, $\mathrm{C}_{\mathrm{T}}$, que ainda será decomposta, pode ser estimada pela expressão:

$$
C_{r}=C_{i}-C_{t}=C_{i} e^{-k t}
$$

o que matematicamente se traduz:

$$
\mathrm{C}_{\mathrm{r}}=\mathrm{C}_{\mathrm{o}} \mathrm{e}^{(-\mathrm{k} . \mathrm{t})} \quad \text { ou } \quad \mathrm{C}_{\mathrm{t}}=\mathrm{C}_{\mathrm{o}}\left[1-\mathrm{e}^{(-\mathrm{k} . \mathrm{t})}\right]
$$

onde $k$ é a constante de velocidade de primeira ordem, expressa por unidade de tempo ${ }^{-1}$; $\mathrm{C}$ é a quantidade de matéria orgânica remanescente no tempo t; $C_{t}$ é a quantidade acumulada de matéria orgânica decomposta e $C_{o}$ a quantidade inicial de matéria orgânica incorporada ao solo. 
A constante $\mathrm{k}$ em termos práticos, constitui-se em uma forma de comparar-se a degradabilidade de materiais orgânicos, em função de sua natureza e condições de incubação. Por meio da constante $\mathrm{k}$ é ainda possível calcular-se a meia-vida do material orgânico estudado $\left(t_{1 / 2}\right)$, sendo calculada pela expressão:

$$
\mathrm{t}_{1 / 2}=\ln 2 / \mathrm{k}
$$

Reddy et al. (1986) descrevendo resultados de Hagin \& Amberger (1974) relataram que os açúcares possuem valores de 1,15 dia $^{-1}$ e 0,6 dias, respectivamente para a constante de velocidade de primeira ordem e meia-vida. Para a celulose encontraram valores de $0,0495 \mathrm{dia}^{-1}$ e 14,0 dias e para a lignina os valores foram de $0,0019 \mathrm{dia}^{-1}$ e 364,7 dias.

O modelo de cinética de primeira ordem não leva em consideração um expressivo aumento de biomassa microbiana pela adição de um substrato orgânico. Essa é uma condição que prevalece com fontes prontamente decomponíveis, pois pode haver assim um desbalanço entre outros fatores que se tornam limitantes.

Brunner \& Focht (1984) modificaram esse modelo para incluir a ocorrência de crescimento microbiano após a adição de um material orgânico. Neste caso duas considerações puderam ser feitas; o crescimento microbiano linear ou exponencial. Os autores concluíram que um modelo de cinética admitindo crescimento linear foi eficiente para interpretar os resultados de decomposição de materiais orgânicos adicionados ao solo, como se segue:

$$
C_{t}=C_{o}\left(1-e^{-k_{1} t-\left(k_{2} t^{2}\right) / 2}\right)+k_{0} t
$$


onde $k_{1}$ é a constante de velocidade de primeira ordem, $k_{2}$ é a constante referente ao crescimento microbiano e $k_{o}$ se refere à constante de velocidade de degradação da matéria orgânica do solo.

Outros modelos são também citados, como o empregado por Paul $\&$ Broadbent (1975), em que $C$ é a perda de carbono no tempo $t$, sendo $k$ e $m$ constantes,

$$
\mathrm{C}=\mathrm{kt}^{\mathrm{m}}
$$

Usando o modelo de cinética de primeira ordem adequado, Reddy et al. (1980) descreveram que o carbono de alguns substratos orgânicos decompõem-se em duas ou três fases. O carbono solúvel é decomposto durante a fase inicial e o carbono mais complexo, na fase posterior, mais lentamente. As constantes de velocidade de primeira ordem para a decomposição da palha de arroz, em condições aeróbias, encontradas pelos autores foram: $0,0054 \mathrm{dia}^{-1}$ para a primeira fase e $0,0013 \mathrm{dia}^{-1}$ para a segunda fase, já em condições anaeróbias, encontraram respectivamente para a fase I e para a fase II valores de $0,0024 \mathrm{dia}^{-1} \mathrm{e} 0,0003 \mathrm{dia}^{-1}$.

Para avaliar a decomposição de lodo de esgoto estabilizado com resíduos de madeira e agentes inertes, Dumonet et al. (1985) aplicaram um modelo que englobava simultaneamente leis de velocidade de ordem zero e de primeira ordem, de modo que através das constantes de velocidade estimadas puderam avaliar o efeito dos agentes estabilizadores adicionados.

Morrill et al. (1982) estudando modelos para quantificar a decomposição de pesticidas no solo relataram que as reações de cinética destes compostos seguem basicamente modelos baseados na diminuição da concentração inicial em função de um período de tempo. 


\subsection{Métodos utilizados para estimar a decomposição dos materiais orgânicos}

Aponta-se como métodos de avaliação de processos de decomposição: determinação do nitrogênio mineralizado como $\mathrm{NH}_{4}^{+}$ou como $\mathrm{NO}_{3}{ }^{-}$medida direta da quantidade de matéria orgânica ainda presente como um todo, ou de alguns constituintes químicos específicos; evolução da temperatura, dentre outros (Waksman, 1963).

Vários são os métodos usados para estimar a "respiração do solo" em ensaios de decomposição. Os métodos que medem a "respiração total" incluem além da atividade microbiológica, a respiração de raízes e pequenos animais.

$\mathrm{O} \mathrm{CO}_{2}$ proveniente da respiração dos microrganismos decompositores, medido nesse estudo, pode ser conduzido em condições de laboratório, com a incubação de diferentes materiais em amostras de solo com umidade e temperatura controladas.

$\mathrm{O} \mathrm{O}_{2}$ pode ser fornecido de diversas maneiras: sem fluxo de ar, com retenção passiva de $\mathrm{CO}_{2}$, e com fluxo de ar, contínuo ou intermitente, pelo sistema chamado de aeração forçada. O primeiro tipo, empregado nesse estudo é de simples utilização, principalmente quando se tem um grande número de tratamentos envolvidos, porém pode se tornar limitante em ensaios prolongados. Eira \& Paccola (1980), em estudo sobre efeito dos inoculantes na compostagem de torta de filtro das usinas de cana de açúcar, concluíram não haver diferença entre os dois métodos. 
$\mathrm{O} \mathrm{CO}_{2}$ emanado do sistema é absorvido por uma solução alcalina, geralmente o hidróxido de sódio, de modo a estabelecer um sistema de equilíbrio entre ácido e base, no qual predominam íons $\mathrm{OH}^{-}$e $\mathrm{CO}_{3}{ }^{2-}$. $\mathrm{A}$ quantificação desse $\mathrm{CO}_{2}$ normalmente é efetuada através de titulação, com solução padrão ácida, após precipitação do íon carbonato presente. Métodos instrumentais como a espectrometria de infra vermelho ou cromatografia gasosa também podem ser empregadas (Rodella, 1996).

$\mathrm{O}$ autor ainda comentou que o uso do método condutimétrico (Saboya \& Rodella, 1995) pode ser uma alternativa interessante. Baseia-se no fato de que a condutividade elétrica de uma solução alcalina decresce à medida em que o $\mathrm{CO}_{2}$ é absorvido, ou seja, quando o íon $\mathrm{OH}^{-}$reage com o $\mathrm{CO}_{2}$ para produzir $\mathrm{CO}_{3}{ }^{2-}$. $\mathrm{O}$ fenômeno ocorre porque a mobilidade do íon hidróxido é bem mais elevada do que a da maioria dos ânions, inclusive do íon carbonato.

As medidas de "respiração" conduzidas em laboratório podem ser controladas, não sendo portanto afetadas pelos efeitos ambientais de temperatura e umidade, como ocorreria em estudos de campo.

\subsubsection{A decomposição avaliada através da respirometria}

Stotzky (1965) destacou as vantagens da medida da respiração dos microrganismos como índice da atividade microbiológica do solo e, conseqüentemente, da decomposição de materiais orgânicos. Tanto o consumo de oxigênio como a produção de gás carbônico podem ser 
quantificados, mas a medida de $\mathrm{CO}_{2}$ é a mais empregada, como salientou o autor.

Encontram-se vários métodos para avaliar a liberação de $\mathrm{CO}_{2}$ em processos de decomposição da matéria orgânica. Basicamente os métodos envolvem a extração do gás por simples difusão em uma solução alcalina de $\mathrm{NaOH}$ ou $\mathrm{Ba}(\mathrm{OH})_{2}$, ou por extração forçada, envolvendo sucção ou pressão, sendo o gás borbulhado numa solução alcalina (Eira \& Paccola, 1980).

Usando método respirométrico, Minhoni et al. (1990) observaram que tratamentos que receberam adição de material orgânico apresentaram maior desprendimento de carbono logo aos primeiros dias de incubação. Tal comportamento reflete a dinâmica de comunidades microbianas no solo, as quais oxidam inicialmente os compostos mais simples, havendo com isso rápido desprendimento de carbono do solo (Minhoni \& Cerri,1987).

Cerri \& Jenkinson (1981) também detectaram maior liberação de carbono nos primeiros dias de incubação de solo, respectivamente com vinhaça, palha de centeio e esterco de curral. A seguir, restam os compostos mais complexos de difícil decomposição e, portanto, que estabelecem um metabolismo microbiano mais lento, evidenciado por taxas inferiores de $\mathrm{CO}_{2}$ desprendido.

A adição simultânea de nitrogênio e fósforo aumentaram significativamente as taxas respiratórias da decomposição de vinhaça, glicose e bagaço de cana, em confronto com as taxas obtidas na incorporação separada de, pelo menos, um desses nutrientes minerais (Minhoni et al.,1990). 
Minhoni \& Cerri (1987) estudaram a decomposição da vinhaça sob efeito da umidade durante a incubação, nos níveis de 40,60 e $80 \%$ da capacidade de retenção do solo. Os autores concluíram que a umidade do solo condicionou a decomposição do resíduo adicionado, em termos de liberação de $\mathrm{CO}_{2}$. O processo foi mais rápido para as parcelas mais secas, porém ao final do período de incubação, as taxas acumuladas de $\mathrm{CO}_{2}$ liberado foram semelhantes, independente do nível de umidade do solo.

A decomposição de folhas de milho, incorporadas em um alfissol foi estudada em um ensaio de respirometria por Vanlauwe et al. (1994). Os autores observaram que a decomposição de uma fração mais resistente pode ser estimulada pela decomposição da fração mais prontamente decomponível. Essa interdependência cinética pode complicar o emprego de modelos mecanísticos que consideram a decomposição da matéria orgânica nativa ou adicionada ao solo, como frações de compartimentos independentes.

$\mathrm{O}$ fenômeno descrito anteriormente é denominado efeito "priming", termo este empregado sobretudo para se designar o processo através do qual a matéria orgânica do solo tem sua decomposição estimulada pela decomposição da matéria orgânica prontamente decomponível. Esse fenômeno introduz erros nos estudos de respirometria, pois se espera que o $\mathrm{CO}_{2}$ liberado seja proveniente apenas do substrato orgânico incubado ao solo. O efeito "priming" é por vezes ignorado em ensaios de respirometria (Minhoni et al., 1990), pois sua avaliação requer a utilização de radioisótopos. 
Tem-se que a respirometria é uma ferramenta para melhor compreensão dos mecanismos decompositores de materiais adicionados ao solo, dando uma idéia de sua atividade microbiana, bem como da velocidade de degradação de diversos materiais. Contudo não se pode ignorar o fato de que, em face da ocorrência de fermentações e processos de respiração aeróbia e anaeróbia, onde o $\mathrm{CO}_{2}$ não é o único produto final do metabolismo, os métodos respirométricos tornam-se impróprios para a quantificação plena de toda a atividade microbiana no solo (Alexander,1967; Waksman, 1963; Minhoni et al., 1990). 


\section{MATERIAL E MÉTODOS}

A decomposição de materiais orgânicos nos diferentes estudos conduzidos foi avaliada por meio da medida de $\mathrm{CO}_{2}$ liberada do solo devido principalmente à atividade microbiana.

No presente estudo foram conduzidos quatro experimentos de respirometria, com delineamento inteiramente casualizado e três repetições, empregando um solo classificado como Latossolo Vermelho Amarelo, fase arenosa, coletado à profundidade de $0 \mathrm{a} 20 \mathrm{~cm}$, em área da Escola Superior de Agricultura "Luiz de Queiroz". Os atributos químicos do solo são apresentados na Tabela 1.

Tabela1-Resultados da análise do solo empregado nos quatro experimentos.

\begin{tabular}{|c|c|c|c|c|c|c|c|c|c|c|c|}
\hline$\underline{\mathbf{H}_{2} \mathbf{O}}$ & pH ${ }_{\mathrm{CaCl}_{2}}$ & $\begin{array}{l}\mathrm{g} \mathrm{kg}^{-1} \\
\mathrm{C}\end{array}$ & $\begin{array}{c}\mathbf{P} \\
\mathbf{m g ~ k g}^{-1}\end{array}$ & $\overline{\overline{\mathbf{K}^{+}}}$ & $\mathrm{Ca}^{++}$ & $\mathrm{Mg}^{++}$ & $\begin{array}{c}\mathbf{A l} \\
\left.. \mathrm{cmol}_{(c)}\right)\end{array}$ & $\underset{\mathrm{gg}^{-1}+\ldots \ldots}{\mathbf{H}+\mathbf{A l}}$ & $\mathbf{S}$ & $\overline{\text { CTC }}$ & $\begin{array}{l}\mathrm{V} \\
\% \\
\end{array}$ \\
\hline, 7 & 4,6 & 11,2 & 19,7 & 0,15 & 1,18 & 0,59 & 0,12 & 2,00 & 1,92 & 3,91 & 49 \\
\hline
\end{tabular}

\subsection{Caracterização dos materiais utilizados}

Os materiais orgânicos estudados apresentaram características variáveis em função dos objetivos de cada estudo. Assim, foram considerados desde reagentes de laboratório até resíduos industriais com expressiva 
concentração de matéria orgânica. A seguir são mencionados os materiais orgânicos estudados com uma breve descrição de suas características químicas de acordo com Bobbio (1989) e Stecher (1960):

Ácido cítrico: ácido orgânico monohidratado de fórmula bruta $\mathrm{C}_{6} \mathrm{H}_{8} \mathrm{O}_{7} \cdot \mathrm{H}_{2} \mathrm{O}$. Composto largamente distribuído em tecidos animais e vegetais, produzido industrialmente por fermentação de fungos e também extraído de frutas citricas.

Ácido húmico: produto complexo resultante da degradação da matéria orgânica no solo, considerado como a fase final estável desse processo. Pouco solúvel em água e solúvel em soluções alcalinas de hidróxidos e carbonatos.

Ágar: é uma importante goma, empregada intensamente como cultura para microrganismos. Constituída por dois polissacarídios: agarose e agaropectina. Apresenta-se como um pó transparente, inodoro, insolúvel em água fria ou álcool e pouco solúvel em água quente, gelificando-se ao esfriar. É extraído de algas.

Amido: importante carboidrato formado por uma mistura de dois polissacarídios denominados amilose e amilopectina, em proporções que variam conforme a espécie vegetal e grau de maturação das plantas. Constitui a mais importante reserva de nutrição de todas as plantas superiores, ocorrendo principalmente em sementes, tubérculos, rizomas e bulbos.

Bagaço de cana-de-açúcar: subproduto da indústria sucro-alcoleira, resultante do esmagamento dos colmos para extração do caldo, na fabricação de açúcar e álcool. Usado para fornecimento de energia através de sua queima nas 
caldeiras. Apresenta em média $38 \%$ de celulose, $34 \%$ de hemicelulose e $11 \%$ de lignina.

Celulose: é o mais abundante polissacarídio, encontrado com maior freqüência na natureza e um dos principais constituintes da parede celular dos vegetais superiores. A celulose no seu estado mais puro é extraída das fibras de algodão, representando $98 \%$ do peso seco.

Glicerol: é um constituinte comum a todos os óleos e gorduras de fórmula bruta $\mathrm{C}_{3} \mathrm{H}_{6} \mathrm{O}_{6}$. Líquido incolor, extremamente solúvel em água e etanol, apresenta propriedades químicas próprias dos grupos hidroxílicos.

Isolado de Proteína de Soja: é um subproduto da extração de óleo de sementes de soja, de onde obtêm-se a farinha de soja desengordurada como resíduo. Este quando seco e moído, é submetido à um tratamento com etanol para fornecer o extrato proteico.

Lignina: é um polímero muito complexo formado por uma combinação de unidades de fenilpropanol, arranjados em três dimensões. É considerada a principal fonte da matéria húmica do solo. Devido a sua estrutura polifenólica muito estável, sua degradação é um processo relativamente lento.

Lodo de tratamento de esgoto urbano: material bastante heterogêneo originado após processamento de resíduos domésticos, podendo ou não ser reunido a resíduos industriais. Sua composição é bastante variável, dependendo de sua procedência.

Óleo de soja: óleos vegetais são formados essencialmente por ésteres de ácidos carboxílicos. Estes ésteres derivam de um álcool apenas, o 
glicerol e, por isso, se designam glicerídeos e são classificados genericamente como lipídios simples.

Palha de cana-de-açúcar: considerado como resíduo da colheita da cultura da cana de açúcar, geralmente permanece nas áreas de plantio. Composto principalmente por folhas e ponteiros. É pois, um material de natureza fibrosa e elevado teor de celulose.

Pectina: são polímeros do ácido galacturônico e fazem parte da estrutura da lamela média das células vegetais. Encontrada principalmente em tecidos pouco rijos, como no albedo das frutas cítricas e na polpa de beterraba. Solúvel em água e insolúvel em álcool e outros solventes orgânicos.

Resíduo da fabricação de café solúvel: resíduo líquido da fabricação de café solúvel, misturado às águas de lavagem dos equipamentos industriais com hidróxido de sódio. Caracteriza-se por ter baixa concentração de sólidos, predominando entre eles os sólidos orgânicos e na sua maior parte, os dissolvidos. O resíduo apresenta baixo potencial de acidez, baixa concentração relativa de carbono orgânico, baixa relação $\mathrm{C} / \mathrm{N}$, mostrando boas condições de degradabilidade.

Sacarose: é o dissacarídio mais importante, tanto pela quantidade e freqüência com que é encontrado na natureza, como pela sua importância na alimentação humana. Apesar de suas fontes principais serem a cana de açúcar e a beterraba, a sacarose é encontrada em todas as plantas que realizam o processo fotossintético, em sementes, folhas, frutos, flores e raízes. 
Tanino: trata-se de um derivado da glicose relacionado ao éster pentadigaloil, de fórmula bruta $\mathrm{C}_{76} \mathrm{H}_{52} \mathrm{O}_{46}$. Classificado como pigmento natural, trata-se de um glicosídeo amplamente distribuído em plantas. Com a maturação dos frutos, perdem-se grandes quantidades de taninos.

Vinhaça: resíduo líquido da destilação de mosto para a fabricação de álcool. Apresenta alta proporção de seus constituintes orgânicos na forma solúvel, como glicerol e ácidos orgânicos, compostos esses de imediata degradação no solo.

A composição química dos resíduos industriais utilizados no experimento é apresentada na Tabela 2.

Tabela 2-Resultados da análise química de alguns dos compostos orgânicos utilizados.

\begin{tabular}{|c|c|c|c|c|c|}
\hline Material & pH & $\begin{array}{l}\mathbf{C} \\
\%\end{array}$ & $\mathbf{N}$ & $\begin{array}{c}\mathbf{P}_{2} \mathbf{O}_{5} \\
\mathbf{g ~ k g}^{-1}\end{array}$ & $\mathbf{K}_{2} \mathbf{O}$ \\
\hline Resíduo de café & 7,8 & 0,34 & 0,09 & 0,01 & 0,14 \\
\hline Vinhaça & 4,8 & 1,25 & 0,85 & 0,16 & 6,60 \\
\hline Lodo de esgoto & 9,8 & 18,80 & 22,94 & 20,15 & 1,58 \\
\hline
\end{tabular}

\subsubsection{Determinação da natureza orgânica de um material}

Para caracterizar um material como sendo de natureza orgânica, deve-se conhecer o teor de carbono total desse material. O dicromato de potássio, $\mathrm{K}_{2} \mathrm{CrO}_{7}$, é o agente mais empregado nas determinações de carbono orgânico por via úmida em solos ou resíduos orgânicos. A oxidação dos compostos orgânicos pelo dicromato é exemplificada a seguir com a glicose:

$$
\mathrm{C}_{6} \mathrm{H}_{12} \mathrm{O}_{6}+4 \mathrm{Cr}_{2} \mathrm{O}_{7}^{2-}+32 \mathrm{H}^{+} \rightarrow 6 \mathrm{CO}_{2}+22 \mathrm{H}_{2} \mathrm{O}+8 \mathrm{Cr}^{3+}
$$


A equação química acima mostra a oxidação completa de um composto orgânico, no caso por sua transformação em $\mathrm{CO}_{2}$ e $\mathrm{H}_{2} \mathrm{O}$. Em materiais mais complexos, a extensão da oxidação depende principalmente, da natureza dos compostos presentes, do tempo da reação e da intensidade de calor fornecido. Portanto, dependendo das condições analíticas, o carbono oxidado pelo ín dicromato pode apenas representar uma fração mais facilmente oxidável, do carbono orgânico total.

Para se estabelecer as doses em que os materiais foram incorporados, tomou-se sempre como referência a mesma quantidade de carbono orgânico total, determinada pelo método de oxidação com $\mathrm{K}_{2} \mathrm{Cr}_{2} \mathrm{O}_{7}$ em presença de ácido sulfúrico, sob aquecimento externo, conforme descrito em Rodella \& Alcarde (1994).

Na Tabela 3 encontram-se os diferentes compostos orgânicos utilizados e as quantidades de carbono orgânico total determinadas pelo método do dicromato de potássio.

Tabela 3-Compostos orgânicos e respectivas quantidades de carbono orgânico total.

\begin{tabular}{lclc}
\hline \hline MATERIAL & $\begin{array}{c}\text { CARBONO ORGÂNICO } \\
\text { TOTAL (\%) }\end{array}$ & MATERIAL & $\begin{array}{c}\text { CARBONO ORGÂNICO } \\
\text { TOTAL (\%) }\end{array}$ \\
\hline Glicerina & 44,72 & Pectina & 34,92 \\
Sacarose & 41,48 & Ácido Húmico & 39,63 \\
Proteína & 41,21 & Óleo de soja & 96,25 \\
Celulose & 40,51 & Amido de Milho & 37,70 \\
Ágar & 36,36 & Lignina & 49,27 \\
Tanino & 39,93 & Bagaço de Cana & 49,34 \\
Ácido Cítrico & 25,15 & Palha de Cana & 42,58 \\
\hline \hline
\end{tabular}


Cada material foi adicionado ao solo na quantidade de $333 \mathrm{mg}$ de carbono orgânico total que mostrou ser, através de ensaios preliminares a quantidade ideal de carbono orgânico para as condições do estudo. Este valor corresponde aproximadamente à quantidade de carbono nativo do solo, decomposta em tratamentos que não receberam adição de material orgânico.

\subsection{Caracterização dos experimentos}

O método escolhido para os experimentos de respirometria foi o da retenção passiva, que consta basicamente da coleta de $\mathrm{CO}_{2}$ desprendido do solo em um volume conhecido de solução padronizada de $\mathrm{NaOH}$, em sistema fechado, para testar a aplicação do modelo de cinética de primeira ordem à decomposição dos diferentes materiais orgânicos no solo.

\subsubsection{Experimento 1. Decomposição de diferentes compostos orgânicos no solo}

Através dos compostos estudados procurou-se representar os principais constituintes da fração orgânica dos materiais vegetais. Nesse sentido, as seguintes substâncias foram consideradas: sacarose, amido, celulose, lignina, tanino, pectina, ácido cítrico, glicerol, triglicérides (óleo de soja), gomas (ágar) e proteína de soja. Incluiu-se ainda o ácido húmico, importante constituinte da matéria orgânica do solo.

O experimento foi conduzido em casa-de-vegetação de forma que 1 $\mathrm{kg}$ de solo seco, uma vez retiradas manualmente as raizes, foi destorroado, 
passado em peneira de $4 \mathrm{~mm}$ de abertura de malha e transferido para pote de vidro de 2 litros, com boca larga, provido de tampa plástica vedante, com $10 \mathrm{~cm}$ de diâmetro e $17 \mathrm{~cm}$ de altura.

Incorporou-se à massa de solo de cada pote a quantidade de material orgânico em estudo, adicionando-se em seguida água destilada na quantidade que corresponde a $50 \%$ da capacidade de retenção de água do solo. Posteriormente, revolveu-se o solo, a fim de promover a devida aeração. Incluise também um tratamento testemunha, sem incorporação de material orgânico.

Sobre a superficie do solo em cada pote de incubação foi colocado um frasco plástico de $100 \mathrm{~mL}$ de capacidade contendo $20 \mathrm{~mL}$ de solução de $\mathrm{NaOH}$ de concentração aproximadamente $0,5 \mathrm{~mol} \mathrm{~L}^{-1}$, exatamente determinada, para absorver $\mathrm{o} \mathrm{CO}_{2}$ liberado do solo. Esses frascos foram trocados periodicamente por outros contendo solução de $\mathrm{NaOH}$ isenta de íons carbonato, para a captação de $\mathrm{CO}_{2}$ durante o novo período.

A freqüência de trocas variou, de 10 a 96 horas, pois o objetivo era impedir que a capacidade de absorção de $\mathrm{CO}_{2}$ pela solução de $\mathrm{NaOH}$ fosse ultrapassada.

Os frascos, após as trocas, foram colocados em banho de água à temperatura ambiente por aproximadamente uma hora, a fim de promover estabilização da temperatura. No mesmo banho foram também colocados frascos com solução pura de $\mathrm{NaOH}$ e de $\mathrm{Na}_{2} \mathrm{CO}_{3}$, previamente preparadas, para calibração do método condutimétrico, empregado para a quantificação do $\mathrm{CO}_{2}$.

Nesse método a calibração é efetuada preparando-se misturas de soluções padrão de $\mathrm{NaOH}$ e $\mathrm{Na}_{2} \mathrm{CO}_{3}$, em proporções diversas, obtendo-se concentrações equivalentes em carga de ânions. Cada solução pode ser 
relacionada à uma hipotética quantidade de $\mathrm{CO}_{2}$ que, se efetivamente absorvida, resultaria nas mesmas concentrações de $\mathrm{CO}_{3}^{2-}$.

As medidas de condutividade elétrica foram efetuadas em condutivímetro marca DIGIMED, modelo CD21, empregando célula com valor de constante próxima a $1 \mathrm{~cm}^{-1}$, com correção de temperatura de leitura para $25^{0} \mathrm{C}$.

A quantidade em miligramas de $\mathrm{CO}_{2}$ absorvido (m) foi calculada pela expressão:

$$
\mathrm{m}=\frac{\mathrm{V} \times \mathrm{M} \times 22,005 \times\left(\mathrm{C}_{1}-\mathrm{C}_{\underline{X}}\right)}{\left(\mathrm{C}_{1}-\mathrm{C}_{2}\right)}
$$

onde $V$ e $M$ são respectivamente, o volume de solução de $\mathrm{NaOH}$ empregada na absorção do $\mathrm{CO}_{2}$ e sua concentração em mol L $\mathrm{L}^{-1}$. $C_{x}$ é a condutividade elétrica da amostra, $C_{1}$ é a medida da condutividade elétrica da solução padrão de $\mathrm{NaOH}$ e $C_{2}$ é a medida da condutividade elétrica da solução padrão de $\mathrm{Na}_{2} \mathrm{CO}_{3}$.

Aos dados de produção de $\mathrm{CO}_{2}$ foi aplicado o modelo de cinética de primeira ordem, apesar de inúmeros modelos de cinética poderem ser aplicados (Alexander \& Scow,1989). Optou-se pelo de primeira ordem, por sua simplicidade, sendo que através da constante de velocidade obtida, pode-se avaliar diretamente a intensidade da degradação do material orgânico no solo. Para o ajuste destes dados, em função do tempo de incubação, empregou-se o programa CFT4 de ajuste multiparamétrico em linguagem BASIC (Meites, 1978).

As curvas de $\mathrm{CO}_{2}$ dos tratamentos que receberam material orgânico foram obtidas, descontando-se a contribuição da testemunha, na tentativa de 
obter-se a curva representativa da degradação apenas do material orgânico em estudo.

Para o tratamento testemunha, optou-se pelo uso do modelo de cinética de primeira ordem que considera duas fases:

$$
\mathrm{C}=\mathrm{C}_{1}\left[1-\mathrm{e}^{\mathrm{k}_{1} \mathrm{t}}\right]+\mathrm{C}_{2}\left[1-\mathrm{e}^{\mathrm{k}_{2} \mathrm{t}}\right]
$$

obtendo-se então duas constantes de velocidade.

As fontes orgânicas, incluindo-se a testemunha com solo, formaram 13 tratamentos estudados em 3 repetições, totalizando 39 parcelas experimentais. O período de incubação foi de 58 dias.

\subsubsection{Experimento 2. Efeito da temperatura na decomposição dos compostos orgânicos no solo}

Materiais com diferentes graus de resistência à decomposição: sacarose, pectina e tanino foram incorporados em $1 \mathrm{~kg}$ de solo, em câmaras de incubação, tipo B.O.D., com controle de temperatura a $34^{\circ} \mathrm{C}, 28^{\circ} \mathrm{C}$ e $22^{\circ} \mathrm{C}$. Esses valores foram escolhidos para se obter uma faixa relativamente ampla de variação de temperatura, englobando-se inclusive a faixa ótima de temperatura para a atividade microbiana, segundo Parr (1975).

A caracterização básica dos experimentos conduzidos foi efetuada conforme descrito em 3.2.1, excetuando-se que os frascos contendo $\mathrm{NaOH}$ foram substituídos em intervalos de aproximadamente 12 horas.

As curvas de $\mathrm{CO}_{2}$ para os tratamentos que receberam material orgânico também foram obtidas descontando-se a contribuição da testemunha. Optou-se pelo uso do modelo de cinética que considera duas fases, para o 
tratamento testemunha, conforme descrito anteriormente . Para a pectina, aplicou-se o modelo proposto por Brunner \& Focht (1984), conforme explicado em 2.2.2.1.

Considerou-se 4 tratamentos e 3 repetições, totalizando 36 vasos, incluindo-se a testemunha. O período de incubação foi de 13 dias.

\subsubsection{Experimento 3. Decomposição conjunta de compostos orgânicos incubados no solo}

Na decomposição de materiais orgânicos no solo, substâncias com diferentes graus de resistência à decomposição participam simultaneamente do processo. No experimento em questão procurou-se determinar a interrelação entre diferentes substâncias ao sofrerem decomposição. Assim, foram considerados quanto à velocidade de decomposição, as seguintes misturas de materiais:

Sacarose, Sacarose + Celulose, Sacarose + Celulose + Lignina, Palha de Cana de Açúcar e Bagaço de Cana de Açúcar.

Esses materiais também foram incorporados a $1 \mathrm{~kg}$ de solo, conforme descrito em 3.2.1, em quantidades equivalentes à mesma quantidade de carbono orgânico, ou seja, $333 \mathrm{mg}$ de carbono orgânico proveniente de cada material incorporado, também quando considerou-se as misturas.

Para os tratamentos: sacarose, bagaço de cana e palha de cana os dados de produção de $\mathrm{CO}_{2}$ foram ajustados ao modelo que considera apenas uma fase de degradação, enquanto que para o tratamento testemunha e para os tratamentos sacarose+celulose e sacarose+celulose+lignina aplicou-se o modelo 
que considera duas fases, descrito em 3.2.1. Para incluir a curva indicativa do comportamento isolado da sacarose empregou-se apenas a primeira parte da equação do modelo duplo citado anteriormente:

$$
\mathrm{C}=\mathrm{C}_{1}\left[1-\mathrm{e}^{-\mathrm{k} 1 \cdot \mathrm{t}}\right]
$$

A produção de $\mathrm{CO}_{2}$ das 18 parcelas experimentais foi medida durante um período de 63 dias.

\subsubsection{Experimento 4. Decomposição de resíduos orgânicos no solo}

Para complementar o presente estudo optou-se por considerar também a degradação de resíduos orgânicos de diferentes naturezas a saber:

-Efluente da fabricação de café solúvel

- Vinhaça

- Lodo de tratamento de esgoto urbano

A condução do experimento foi efetuada conforme descrito em 3.2.1, ressaltando-se que como a vinhaça e o resíduo de café solúvel são efluentes de natureza aquosa, seu volume foi descontado do volume de água calculado para atingir $50 \%$ da capacidade de retenção de água do solo, de modo que a fração orgânica desses materiais foi degradada nas mesmas condições dos demais materiais.

Aos dados de produção de $\mathrm{CO}_{2}$ do tratamento testemunha, aplicou-se o modelo que considera duas fases distintas. Nos demais tratamentos o modelo utilizado considera apenas uma fase de degradação.

Nos experimentos anteriores a curva de degradação dos diferentes materiais foi obtida descontando-se a contribuição da testemunha. Para estes 
tratamentos esse procedimento mostrou-se inadequado, optando-se por ajustar ao modelo de cinética de primeira ordem a curva referente à decomposição conjunta do carbono orgânico do solo e dos resíduos orgânicos incorporados.

$\mathrm{O}$ período de incubação para as 12 parcelas experimentais foi de 63 dias. 


\section{RESULTADOS E DISCUSSÃO}

\subsection{Experimento 1. Decomposição de diferentes compostos orgânicos no solo}

Conforme pode ser observado na Figura 1, o solo natural, ou seja sem a adição de qualquer material orgânico, mostrou desprendimento de $\mathrm{CO}_{2}$ relativamente elevado, da ordem de $1526 \mathrm{mg}$, indicando alta atividade microbiana. Na realidade, resultados de ensaio de respirometria são empregados para avaliar a biomassa microbiana do solo e por consequiência sua atividade (Alexander, 1967).

De maneira geral, durante os 58 dias de duração do experimento observou-se acentuada produção de $\mathrm{CO}_{2}$ para a maioria das fontes de carbono orgânico estudadas, com exceção do ágar, ácido húmico e da lignina. Para as nove outras fontes a produção média final foi de $970 \mathrm{mg}$ de $\mathrm{CO}_{2}$ provenientes da degradação dos $333 \mathrm{mg}$ de carbono orgânico adicionados aos potes, valor esse bastante superior àquele das três fontes que apresentaram baixa taxa de degradação, conforme pode se comparar através dos dados da Tabela 4 . Nota-se também a elevada porcentagem de carbono decomposto para o óleo de soja, fato este possivelmente explicado pela inadequação do método do dicromato de potássio na quantificação do carbono orgânico total deste material. 


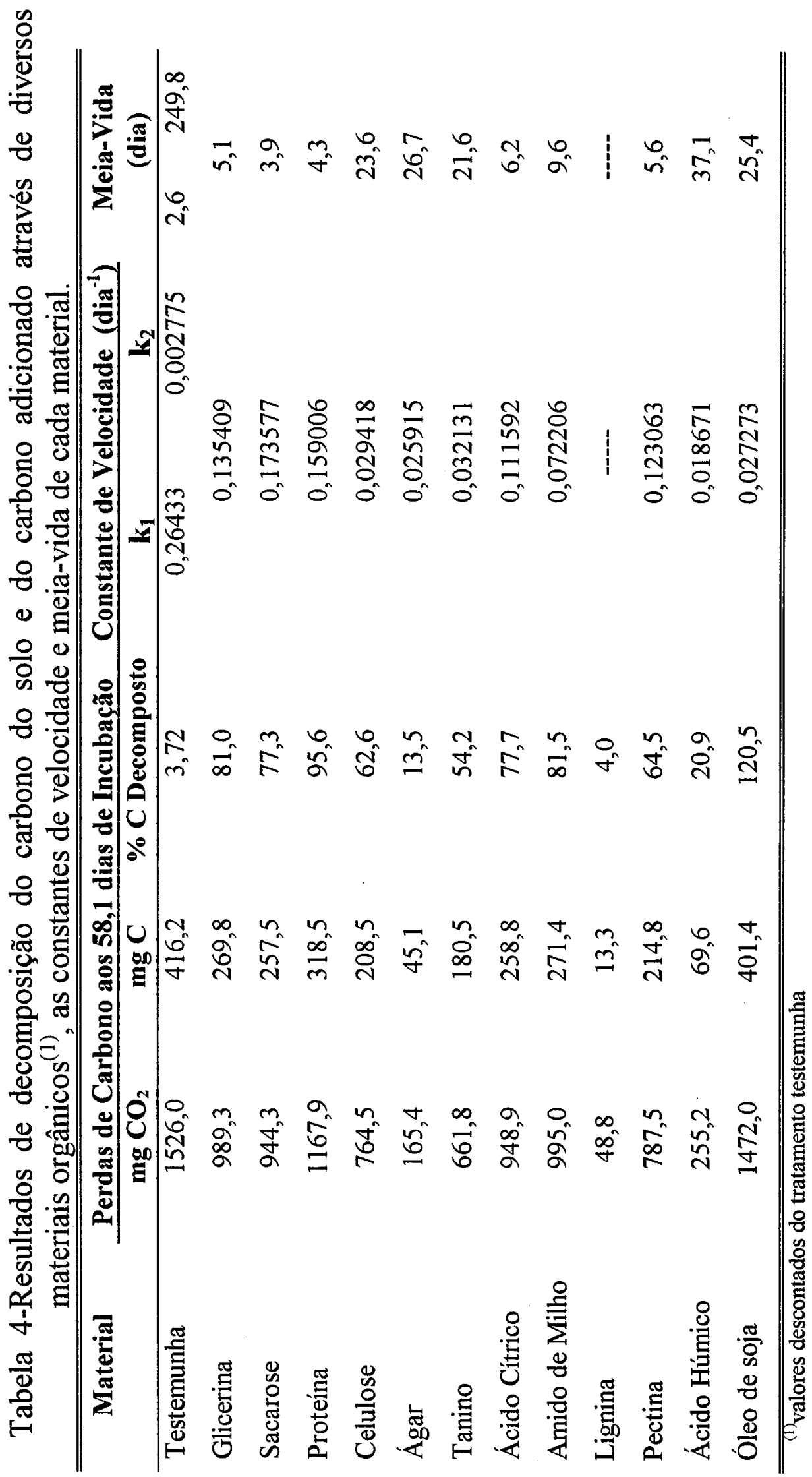


Na Figuras 2, 3 e 4 são mostradas curvas de desprendimento de $\mathrm{CO}_{2}$ em função do tempo de incubação, onde as fontes de carbono orgânico foram reunidas em função da similaridade de comportamento em termos de produção total de $\mathrm{CO}_{2}$.

Pelo exame das curvas de produção acumulada de $\mathrm{CO}_{2}$, não se identifica o período inicial de adaptação dos microrganismos à incorporação do material orgânico, denominado de lag-fase, que confere uma tendência sigmóide à curva de respirometria. Sabe-se que a lag-fase sempre ocorre, mas pode não ser claramente identificável em função da periodicidade das medidas de $\mathrm{CO}_{2}$ desprendido. É bastante nítida sobretudo na degradação de compostos tóxicos no solo como fenóis ou pesticidas e seus derivados. O modelo de cinética de primeira ordem não possibilita o ajuste dos dados referentes à lag-fase.

No modelo de cinética de primeira ordem empregado para o ajuste dos dados de produção de $\mathrm{CO}_{2}$ deste estudo considerou-se apenas uma fração diferenciada quanto à velocidade de decomposição, pois, em função dos valores dos coeficientes de determinação obtidos, não havia vantagem de se ajustar o modelo de duas fases. No caso da testemunha isso não ocorreu, de modo que o modelo com duas fases foi empregado. Os coeficientes de determinação $\left(r^{2}\right)$ para os referidos ajustes foram sempre superiores a $0,97, o$ que evidencia a excelente adequação do modelo proposto ao fenômeno estudado. Assim sendo, infere-se que, dentro do período estudado, os compostos orgânicos se decompuseram em um único estágio. 


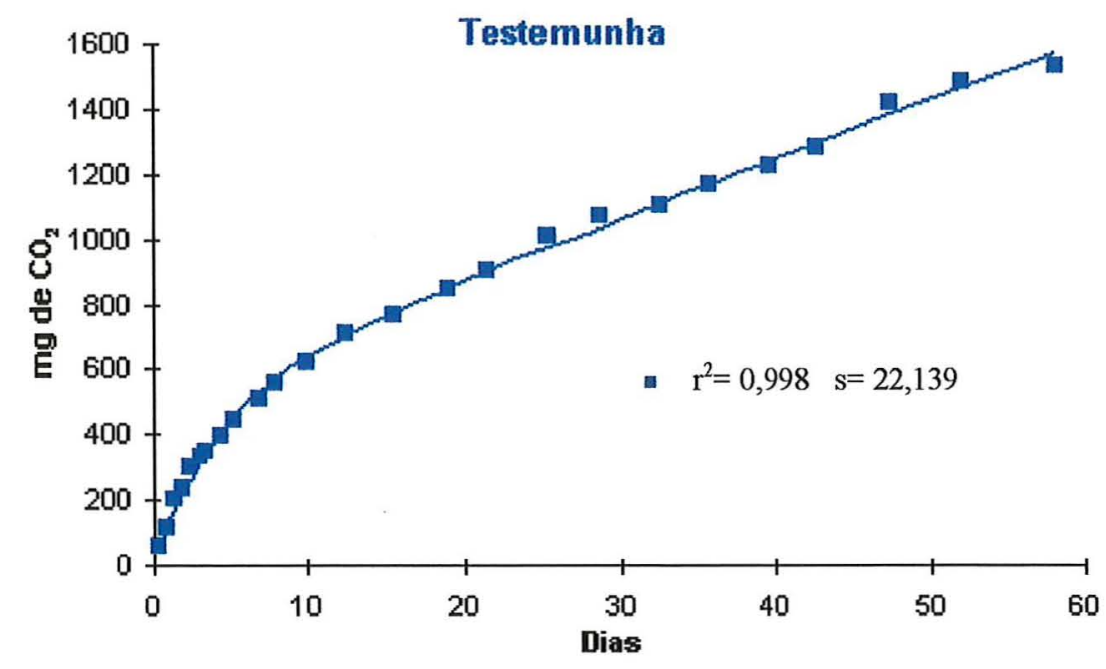

Figura 1-Quantidade acumulada de $\mathrm{CO}_{2}$ liberado do solo em função do tempo de incubação no tratamento testemunha: pontos experimentais e curva ajustada ao modelo de cinética de primeira ordem. Indicação do coeficiente de determinação $\left(\mathrm{r}^{2}\right)$ e do desvio padrão (s).

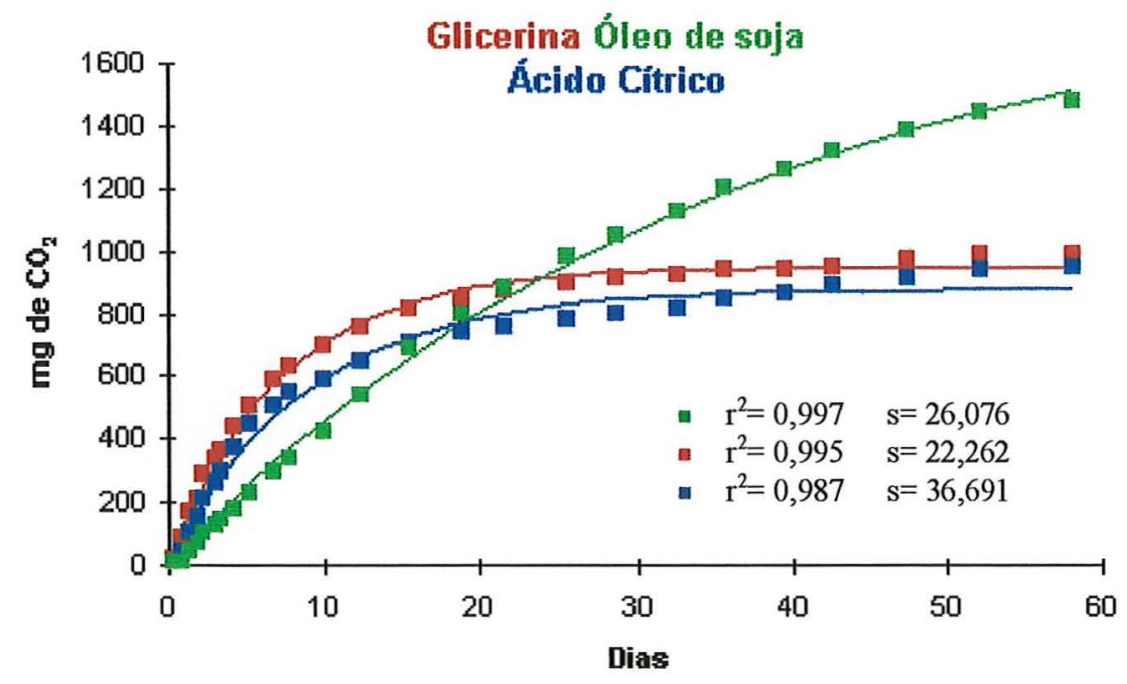

Figura 2-Quantidade acumulada de $\mathrm{CO}_{2}$ liberado do solo em função do tempo de incubação dos compostos orgânicos indicados: pontos experimentais e curva ajustada ao modelo de cinética de primeira ordem. Indicação dos coeficientes de determinação $\left(r^{2}\right)$ e dos desvios padrão (s). 


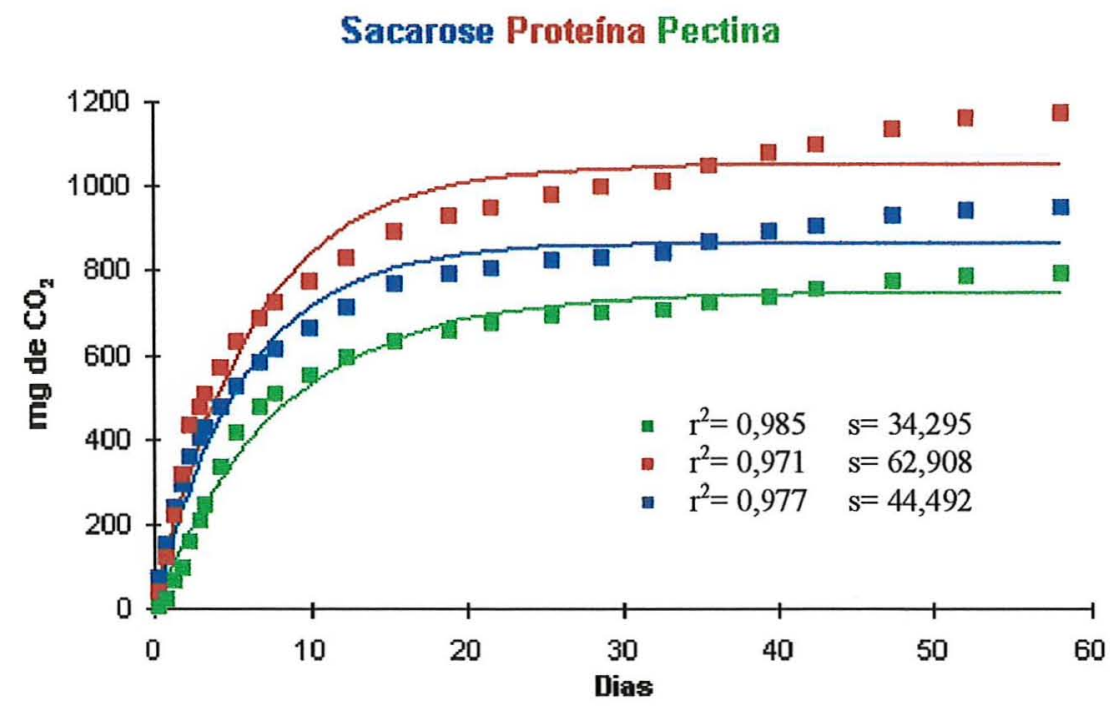

Figura 3-Quantidade acumulada de $\mathrm{CO}_{2}$ liberado do solo em função do tempo de incubação dos compostos orgânicos indicados: pontos experimentais e curva ajustada ao modelo de cinética de primeira ordem. Indicação dos coeficientes de determinação $\left(\mathrm{r}^{2}\right)$ e dos desvios padrão (s).

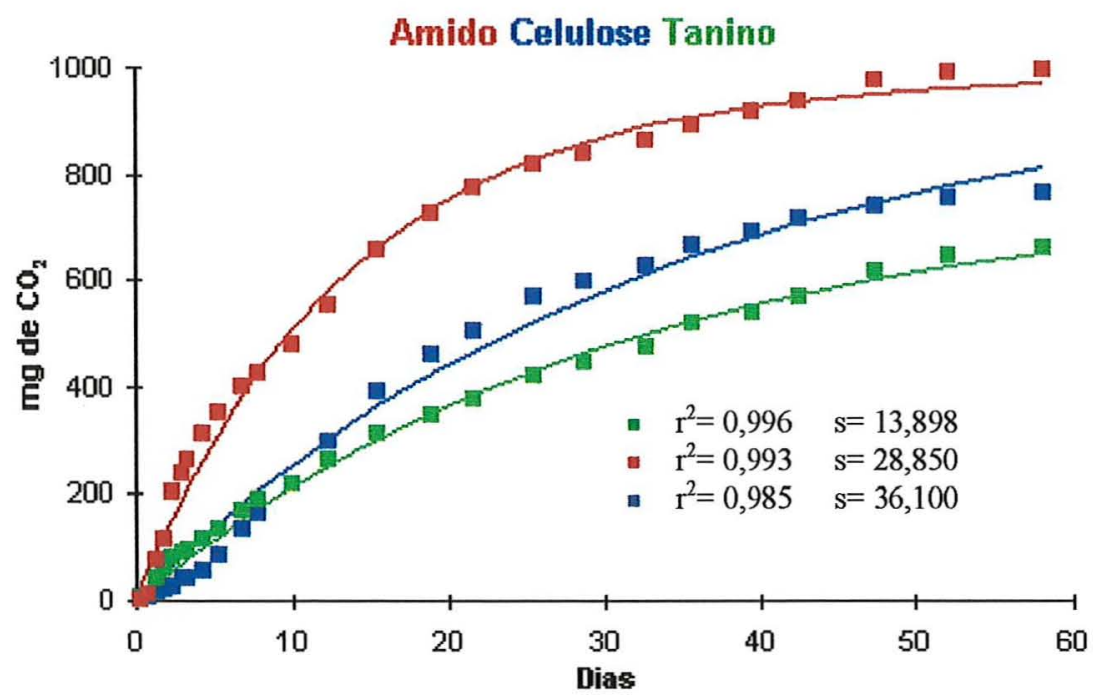

Figura 4-Quantidade acumulada de $\mathrm{CO}_{2}$ liberado do solo em função do tempo de incubação dos compostos orgânicos indicados: pontos experimentais e curva ajustada ao modelo de cinética de primeira ordem. Indicação dos coeficientes de determinação $\left(\mathrm{r}^{2}\right)$ e dos desvios padrão (s). 
As curvas das Figuras 2, 3 e 4 são expressas através dos parâmetros cinéticos apresentados na Tabela 4. É evidente que os diversos materiais se comportam diferentemente quanto à velocidade com que se decompõem. Este fato é demonstrado através de suas constantes de velocidade $\mathrm{k}$ expressas em $\mathrm{dia}^{-1}$, pois quanto maior seu valor, maior a rapidez de decomposição.

É possível ainda comparar as diferentes fontes entre si quanto a esse aspecto, pois pode-se inferir que o amido se decompôs 2,2 vezes mais rapidamente que o tanino, valor esse referente ao quociente das respectivas constantes de velocidade.

Pode-se ressaltar que as constantes de velocidade $\mathrm{k}$ para diferentes materiais não se relacionaram com a porcentagem de carbono decomposto no período. Observando-se os valores de $\mathrm{k}$ para o ágar e para a celulose percebe-se sua proximidade, embora os valores de carbono decomposto sejam bem diferenciados.

Para os dados da lignina não foi possível ajustar o modelo devido à baixa intensidade de degradação do material (4\%), sendo que as quantidades de $\mathrm{CO}_{2}$ desprendidas em certos períodos foram similares a da testemunha.

Além da constante de velocidade, outro parâmetro cinético em geral empregado na análise comparativa de resultados de respirometria é a meia-vida. Embora estes valores tenham sido incluídos na Tabela 4, é necessário ressaltar que, na verdade, todas as conclusões que podem ser obtidas através desse parâmetro são as mesmas que se obtém com a constante de velocidade. 
Obedecendo estritamente a ordem decrescente de velocidade de decomposição, os materiais incubados podem ser relacionados na seguinte sequência: sacarose, isolado de proteína de soja, glicerina, pectina, ácido cítrico, amido, tanino, celulose, óleo de soja, ágar, ácido húmico e lignina. Entretanto, considerando-se a proximidade dos valores determinados para a constante de velocidade, os compostos orgânicos podem ser agrupados conforme mostrado na Tabela 5.

Tabela 5-Diferentes compostos orgânicos agrupados de acordo com sua velocidade de degradação.

\begin{tabular}{|c|c|}
\hline Compostos orgânicos & $\begin{array}{c}\text { Constantes de velocidade } \\
\text { médias }\left(\text { dia }^{-1}\right)\end{array}$ \\
\hline sacarose e proteína & 0,166 \\
\hline ácido cítrico, glicerina e pectina & 0,123 \\
\hline amido & 0,072 \\
\hline tanino, celulose, ágar e óleo de soja & 0,029 \\
\hline ácido húmico & 0,018 \\
\hline lignina & não determinado \\
\hline
\end{tabular}

Observa-se que o comportamento dos carboidratos: sacarose, amido e celulose é coerente com o grau de complexidade da estrutura de suas moléculas. A pectina, sendo também um carboidrato, tem sua ordem de inclusão justificada. A colocação do tanino no mesmo grupo da celulose se justifica pelo fato desse composto ser um tipo de éster relacionado à glicose (Stecher, 1960).

O comportamento da lignina e do ácido húmico pode ser justificado pela ocorrência de grupos fenólicos em suas moléculas, de reconhecida resistência à degradação no solo (Cardoso, 1992). 
Esses resultados concordam com vários autores (Brady, 1989; Minhoni, 1990; Vanlawe et al., 1994) que afirmaram que os açúcares, o amido e as proteínas, são degradados rapidamente, seguidos por hemicelulose, celulose, lignina, gorduras e ceras, que são decompostos muito lentamente.

Do mesmo modo, a cinética de decomposição de restos culturais depositados no solo foi estudado por Jenkinson \& Rayner (1977), que verificaram ser decomposta em menos de um ano a fração ativa do resíduo depositado no solo, representado principalmente por açúcares, proteínas, amido e celulose, enquanto outras frações eram resistentes à decomposição.

\subsection{Experimento 2. Efeito da temperatura na decomposição dos compostos orgânicos no solo}

De um modo geral observou-se que, dentro do período estudado de 13 dias, o efeito da temperatura foi bastante claro nos diferentes materiais incubados, sendo em geral mais expressivo na elevação de 22 para $28^{\circ} \mathrm{C}$, do que para o intervalo de 28 a $34^{\circ} \mathrm{C}$.

Procurou-se estimar a temperatura referente à máxima decomposição calculando-se o ponto de máximo da parábola ajustada aos dados de temperatura e porcentagem de carbono decomposto. Os valores obtidos sugerem que para a sacarose e para a pectina a máxima decomposição ocorreu em temperaturas superiores a $34^{\circ} \mathrm{C}$.

Pode-se também verificar que a temperatura exerceu influência diferenciada sobre a velocidade de degradação dos compostos orgânicos. 
Assim, considerando-se os dados da Tabela 7, nota-se que pelo aumento da temperatura de $22^{\circ} \mathrm{C}$ para $34^{\circ} \mathrm{C}$ ocorreu uma elevação de $21 \%$ na decomposição do carbono orgânico da sacarose, enquanto que para o tanino e pectina foram de $52 \%$ e $5 \%$, respectivamente.

Deve ser mencionado, observando os dados da Tabela 6, que ocorreu uma alteração no comportamento da pectina em relação ao tanino, quando se comparam os resultados dos experimentos 1 e 2, para o mesmo período de incubação, enquanto que para sacarose o comportamento foi similar em ambos.

Tabela 6-Comportamento dos diferentes materiais, no primeiro e no segundo experimento quanto ao desprendimento acumulado de $\mathrm{CO}_{2}$ aos 12,4 dias.

\begin{tabular}{|c|c|c|}
\hline Materiais & \multicolumn{2}{|c|}{$\mathrm{mg} \mathrm{CO}_{2}$ total desprendido aos 12,4 dias } \\
\hline sacarose & 710,0 & 731,1 \\
\hline pectina & 591,7 & 396,6 \\
\hline tanino & 261,8 & 382,3 \\
\hline
\end{tabular}

Esse comportamento pode ser justificado pelo fato de que no experimento 1 , conduzido em casa de vegetação, ocorreram temperaturas máximas sempre mais elevadas que $34^{\circ} \mathrm{C}$, favorecendo a decomposição da pectina. Esta observação concorda com o que foi comentado anteriormente sobre o efeito da temperatura no intervalo de 22 a $34^{\circ} \mathrm{C}$.

O modelo empregado para o ajuste dos dados de produção de $\mathrm{CO}_{2}$ para a sacarose e para o tanino considerou apenas uma única fração de carbono orgânico com velocidade de decomposição característica. Para a pectina, o ajuste do modelo de cinética de primeira ordem foi menos 
eficiente, devido à manifestação da chamada lag-fase. Esta fase de adaptação e crescimento microbiano, é considerada no modelo proposto por Brunner \& Focht (1984), que foi adotado para avaliar a degradação do composto em questão. Para a testemunha, nas três temperaturas estudadas, o modelo de duas fases foi o que melhor se ajustou. Os coeficientes de determinação $\left(\mathrm{r}^{2}\right)$ para os referidos ajustes foram sempre superiores a 0,98 , mostrando a adequação do modelo empregado ao fenômeno estudado.

Conforme pode ser deduzido através dos dados apresentados na Tabela 7, os parâmetros cinéticos indicam que a sacarose foi o composto orgânico que se decompôs mais rapidamente, o que pode ser observado através da constante de velocidade de primeira ordem e da meia-vida. Em sequência de ordem decrescente de velocidade de decomposição aparecem o tanino e a pectina. Nota-se que a $28^{\circ} \mathrm{C}$ as maiores constantes de velocidade são encontradas para a pectina, tanino e para a testemunha; porém a $34^{\circ} \mathrm{C}$ é que encontram-se maiores valores de carbono decomposto durante o período estudado. Cabe ressaltar ainda que o efeito da temperatura se manifestou inclusive na testemunha, ou seja, na degradação do carbono nativo do solo.

Nas Figuras 5, 6, 7 e 8 estão representadas as curvas de liberação de $\mathrm{CO}_{2}$ em função do tempo de incubação, com os respectivos coeficientes de determinação $\left(\mathrm{r}^{2}\right)$ e desvios padrão (s), que indicam a qualidade do ajuste do modelo de primeira ordem aos dados experimentais da sacarose e do tanino, nas três temperaturas estudadas. 


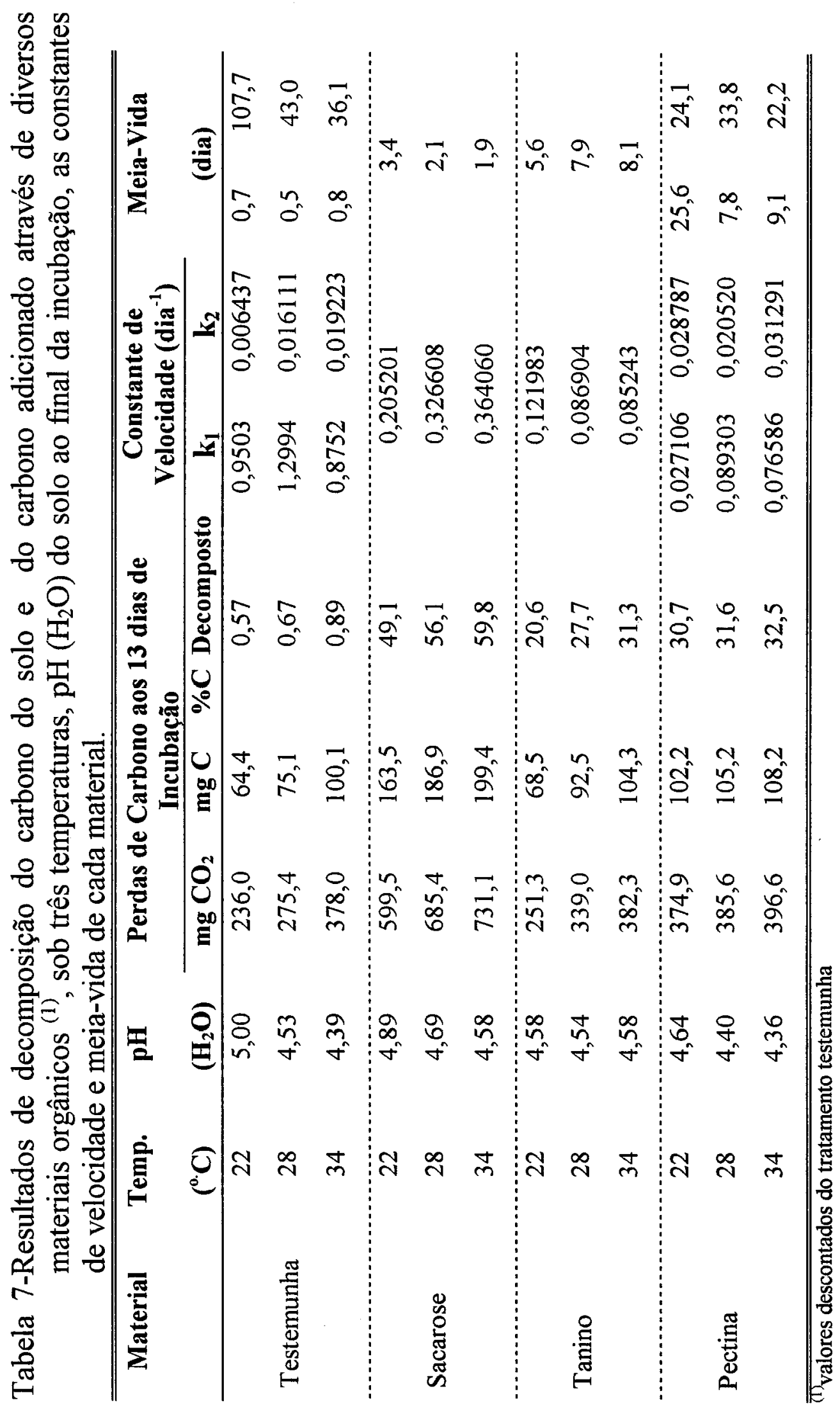


Uma possível interpretação para os resultados obtidos para a pectina é a seguinte: o modelo adotado envolve duas constantes $\mathrm{k}_{1}$ e $\mathrm{k}_{2}$; e como a segunda delas está relacionada à lag-fase, pode-se avaliar o comportamento da pectina em função de $\mathrm{k}_{1}$, após ter transcorrido esta fase. Sendo assim, observou-se que a temperatura de $22^{\circ} \mathrm{C}$ restringiu a velocidade de decomposição, pois a constante $\mathrm{k}_{1}$ para essa temperatura foi de 0,02711 $\mathrm{dia}^{-1}$, valor esse inferior à 0,08931 e $0,07658 \mathrm{dia}^{-1}$ para 28 e $34^{\circ} \mathrm{C}$, respectivamente. A similaridade entre as constantes obtidas a 28 e $34^{\circ} \mathrm{C}$ também foi detectada para as outras substâncias estudadas.

$\mathrm{O}$ efeito da lag-fase não foi detectado nas demais substâncias, apesar de se ter conhecimento da sua existência e sua observação apenas para a pectina pode ser decorrente de um maior grau de complexidade na sua decomposição microbiológica.

A temperatura é um fator que reconhecidamente afeta a cinética de decomposição de materiais orgânicos no solo. Alexander (1967) relatou que a mineralização do carbono no solo é mais lenta em baixas temperaturas e Parr (1975) considerou a faixa de 30 a $35^{\circ} \mathrm{C}$ como sendo a que proporciona a máxima velocidade de decomposição de materiais orgânicos no solo, de modo geral.

As variações no $\mathrm{pH}\left(\mathrm{H}_{2} \mathrm{O}\right)$ do solo estão relacionadas com as temperaturas de incubação para a sacarose e a pectina, bem como para a testemunha, como se pode observar através dos dados exibidos na Tabela 7 , sendo que, de modo geral, o aumento da temperatura causou diminuição no $\mathrm{pH}$ do solo. Este fato pode estar relacionado à excreção de ácidos orgânicos formados de materiais intermediários da degradação de carboidratos no solo. 


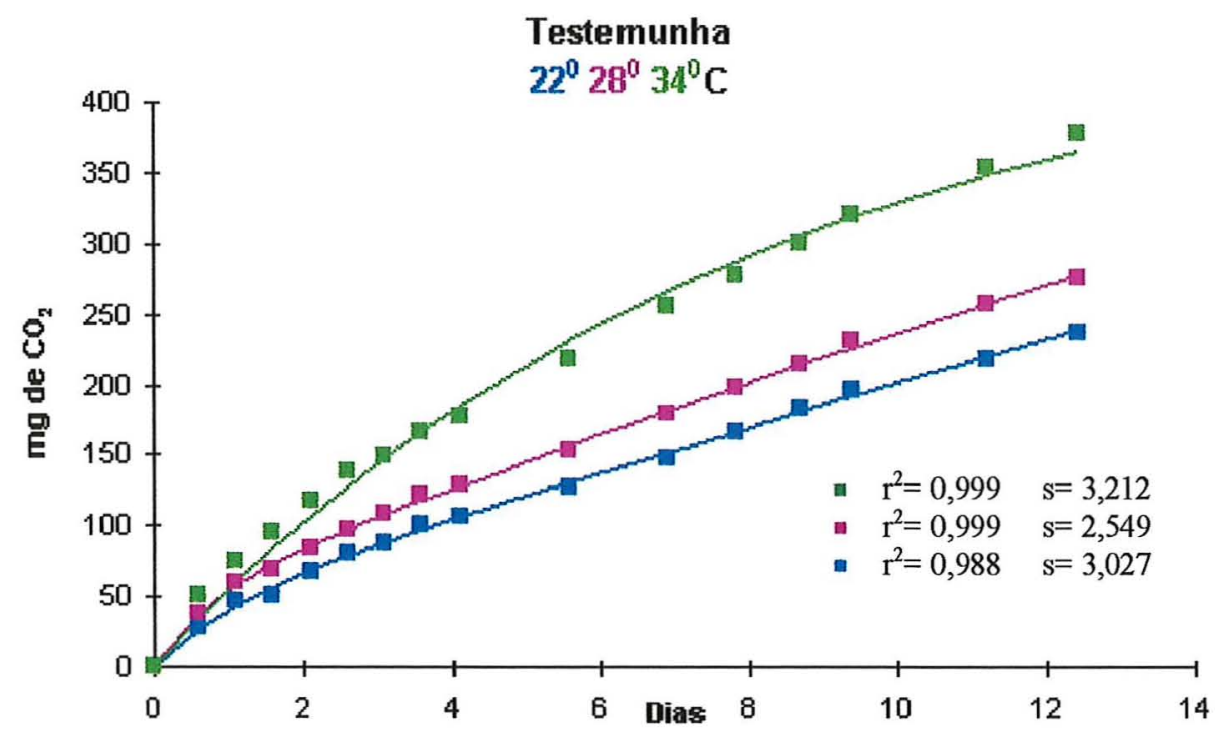

Figura 5-Quantidade acumulada de $\mathrm{CO}_{2}$ liberado do solo em função do tempo de incubação no tratamento testemunha: pontos experimentais e curva ajustada ao modelo de cinética de primeira ordem. Indicação do coeficiente de determinação $\left(r^{2}\right)$ e do desvio padrão (s).

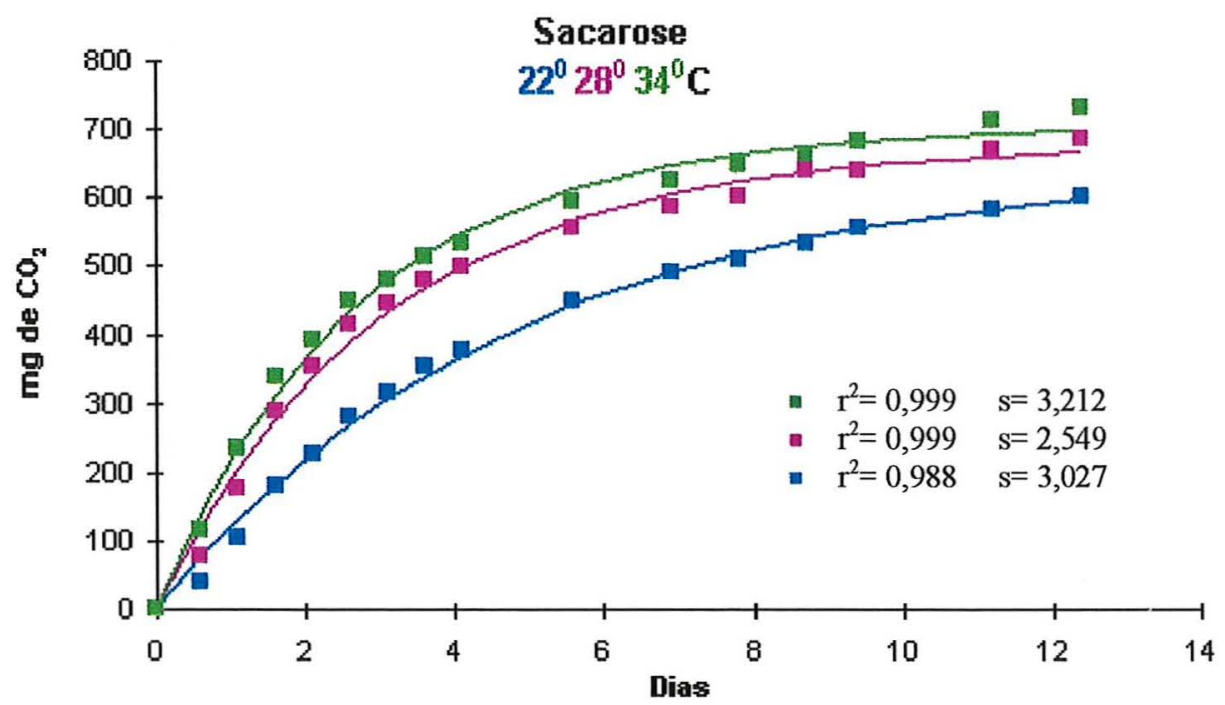

Figura 6-Quantidade acumulada de $\mathrm{CO}_{2}$ liberado do solo em função do tempo de incubação para a sacarose: pontos experimentais e curva ajustada ao modelo de cinética de primeira ordem. Indicação dos coeficientes de determinação $\left(\mathrm{r}^{2}\right)$ e dos desvios padrão (s). 


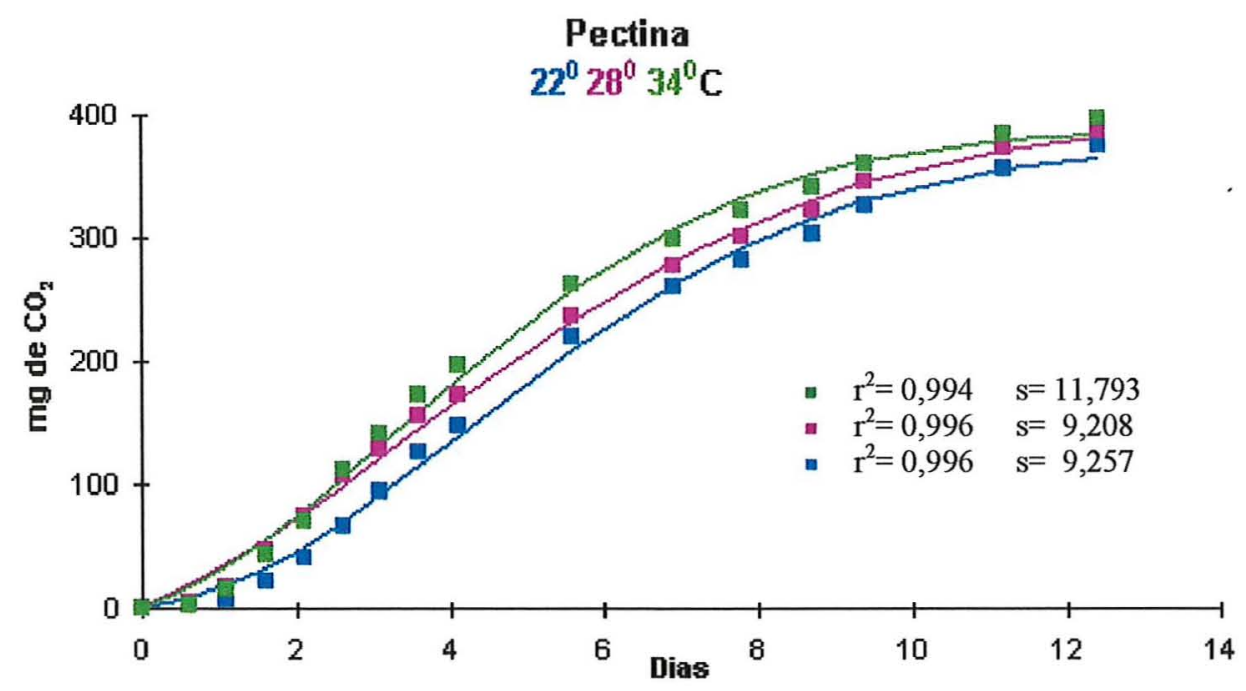

Figura 7-Quantidade acumulada de $\mathrm{CO}_{2}$ liberado do solo em função do tempo de incubação para a pectina: pontos experimentais e curva ajustada ao modelo de cinética de primeira ordem. Indicação dos coeficientes de determinação $\left(\mathrm{r}^{2}\right)$ e dos desvios padrão (s).

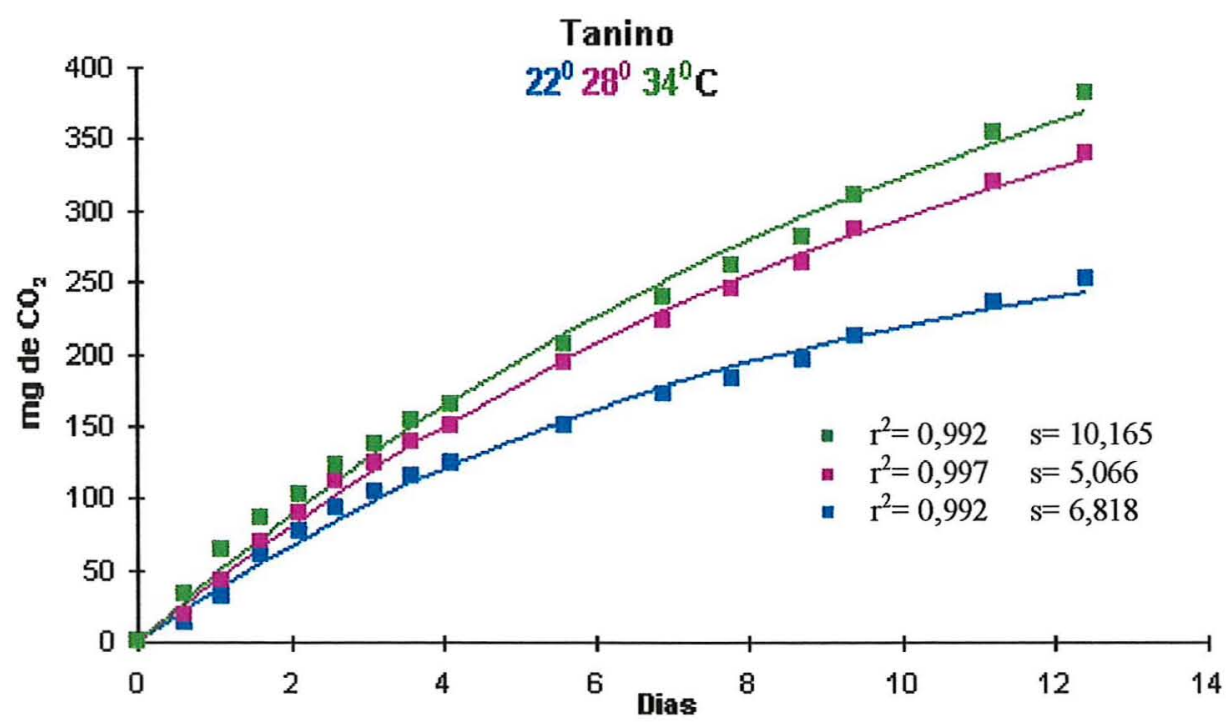

Figura 8-Quantidade acumulada de $\mathrm{CO}_{2}$ liberado do solo em função do tempo de incubação para o tanino: pontos experimentais e curva ajustada ao modelo de cinética de primeira ordem. Indicação dos coeficientes de determinação $\left(\mathrm{r}^{2}\right)$ e dos desvios padrão (s). 
Por outro lado, as variações observadas no $\mathrm{pH}$ do solo também podem ser relacionadas às quantidades totais de $\mathrm{CO}_{2}$ produzidas ao final do período de incubação, como se pode observar na Figura 9.

Essa relação indica que quanto mais acentuada a degradação do material orgânico incubado, expressa pela quantidade de $\mathrm{CO}_{2}$ liberada, mais baixo apresentou-se o $\mathrm{pH}$ do solo, pois provavelmente, os produtos desse processo apresentaram natureza ácida.
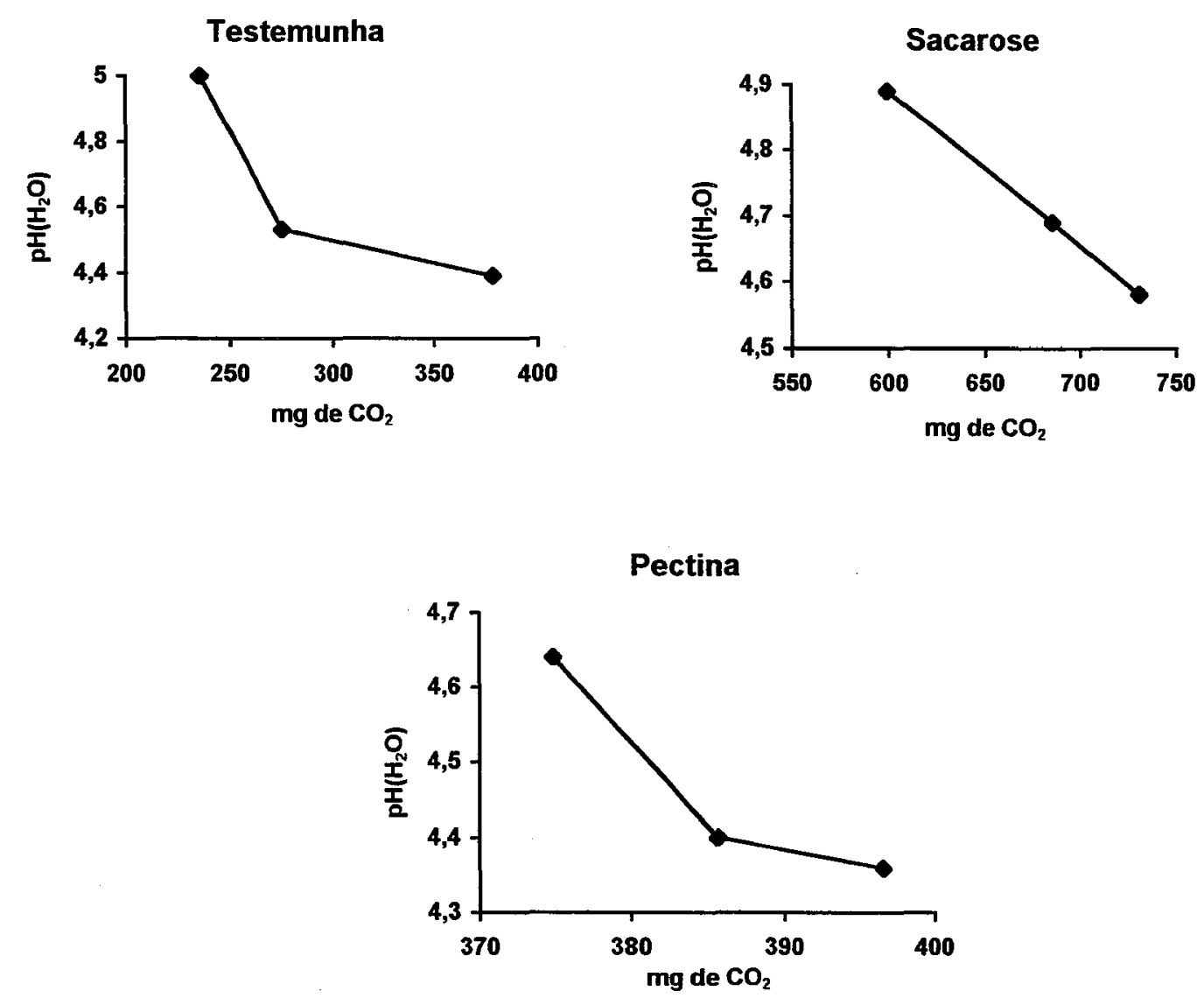

Figura 9-Relação entre $\mathrm{pH}\left(\mathrm{H}_{2} \mathrm{O}\right)$ e quantidade total de $\mathrm{CO}_{2}$ liberada do solo

Compostos orgânicos como a sacarose podem ser incluídos como termo de referência em estudos sobre a degradabilidade de materiais 
orgânicos em geral, como resíduos industriais por exemplo, através de ensaios de respirometria. Como nesses casos, o controle rigoroso da temperatura durante a incubação nem sempre é possível, pode-se recomendar que a temperatura deva se situar pelo menos entre 28 a $34^{\circ} \mathrm{C}$, para minimizar o efeito desse fator de variação.

\section{3 Experimento 3. Decomposição conjunta de compostos orgânicos incubados no solo}

Neste experimento foram incubados ao solo misturas de compostos a fim de se avaliar a adequação do modelo de primeira ordem à um processo de decomposição no qual diferentes etapas provavelmente ocorreriam. Esse fato era esperado pois compostos de diferentes graus de resistência à decomposição microbiológica no solo foram incluídos.

Os parâmetros cinéticos referentes à decomposição da sacarose, sacarose+celulose e da sacarose+celulose+lignina, bem como da testemunha, estão apresentados na Tabela 8.

Os dados de produção de $\mathrm{CO}_{2}$ em função do tempo de incubação para a sacarose foram ajustados ao modelo que considera apenas uma fase de degradação, enquanto que para a mistura de carboidratos e também para a testemunha, o modelo com duas fases forneceu sempre melhores coeficientes de determinação.

Para a mistura sacarose+celulose, por exemplo, o valor de $r^{2}$ aumentou de 0,963 para 0,997, ficando evidente que o modelo de cinética de primeira ordem pode ser empregado para interpretar a decomposição de 
misturas de dois compostos com velocidades distintas, desde que inclua duas sequências que levem em conta essa característica.

Também para a mistura de sacarose+celulose+lignina o modelo de duas sequências foi mais adequado, não havendo ganho na qualidade do ajuste ao se empregar um modelo de três sequências, numa tentativa de representar os três compostos reunidos. Desta forma, seja qual for o papel que a lignina possa ter tido neste tratamento, conforme será considerado a seguir, o certo é que ela não pôde ser relacionada a uma terceira etapa no modelo cinético.

Observando-se a Figura 10 nota-se que a interpretação do comportamento da sacarose e das misturas se mostra relativamente complexo. Para efeito de comparação, juntamente com as curvas de degradação da sacarose+celulose e da sacarose+celulose+lignina, incluiu-se também a curva que seria indicativa do comportamento isolado da sacarose. Isso foi feito empregando-se apenas a primeira parte da equação do modelo duplo citado em 3.2.3. Através desse procedimento parece ter-se uma indicação de que a sacarose atuou de modo aproximadamente semelhante nos três tratamentos.

As quantidades de $\mathrm{CO}_{2}$ liberadas do solo no tratamento envolvendo sacarose+celulose+lignina foram superiores àquelas formadas por sacarose+celulose. Torna-se difícil explicar esse acréscimo, pois esperava-se que a lignina apresentasse um grau ínfimo de decomposição. 


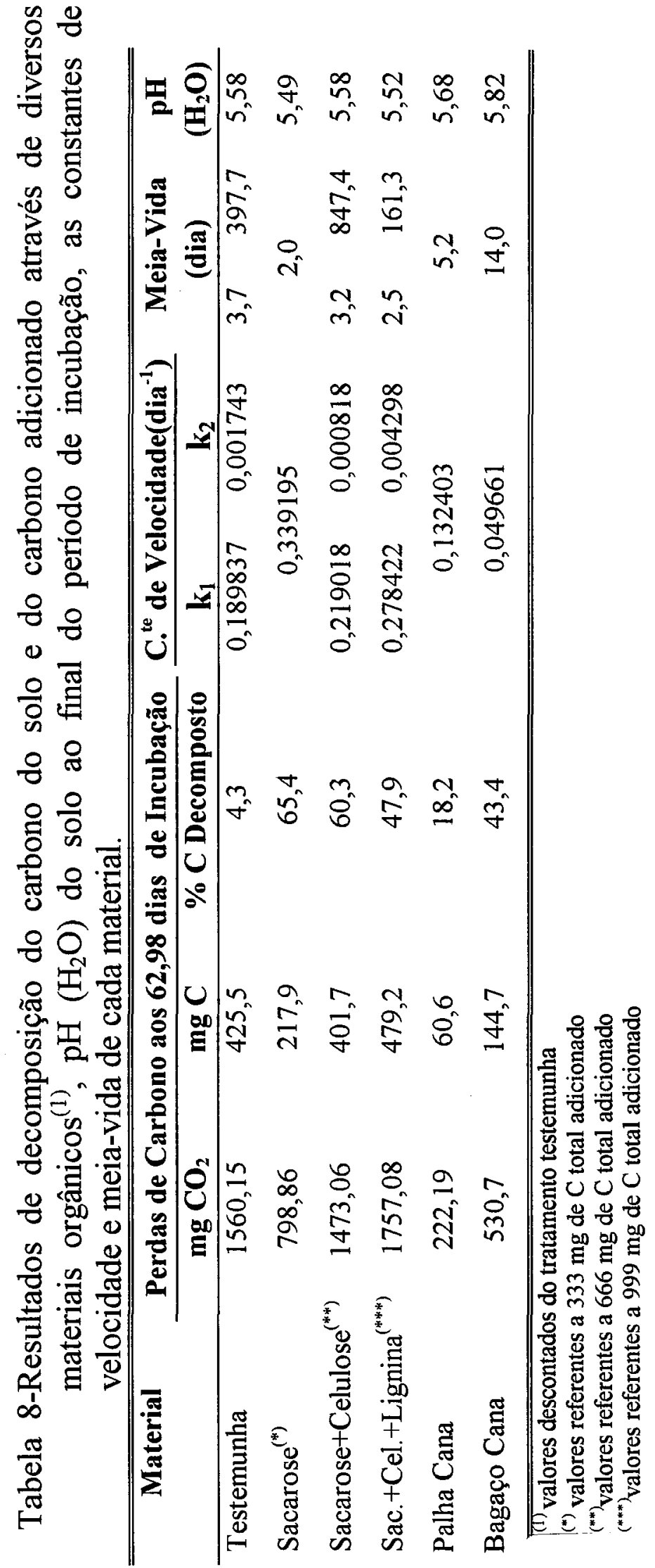



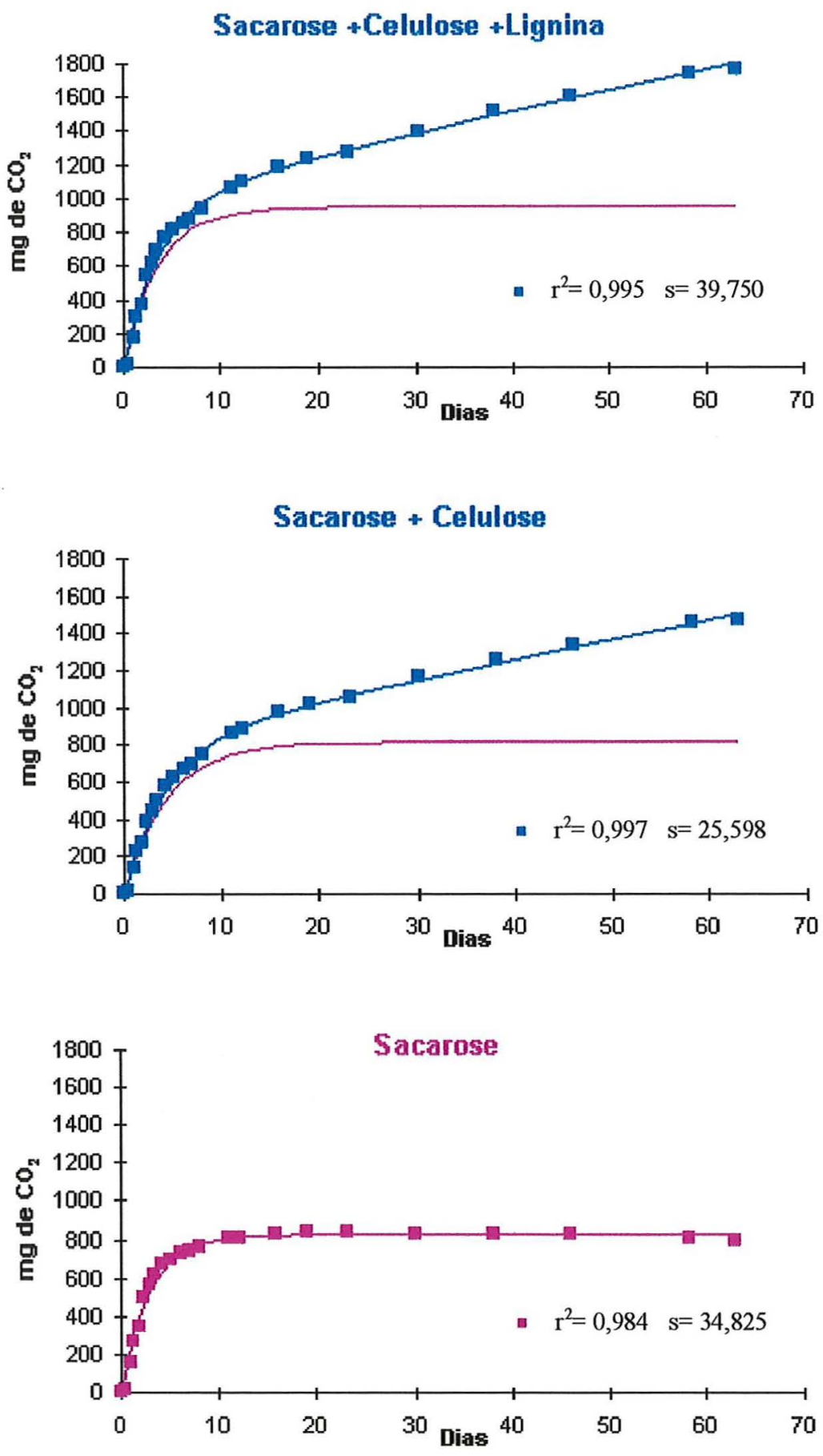

Figura 10-Quantidade acumulada de $\mathrm{CO}_{2}$ liberado do solo em função do tempo de incubação dos compostos orgânicos indicados: pontos experimentais e curva ajustada ao modelo de cinética de primeira ordem. Indicação dos coeficientes de determinação $\left(r^{2}\right)$ e dos desvios padrão (s). 
Acompanhando a degradação da palha e do bagaço de cana através da Figura 11, bem como pelos dados da Tabela 8, nota-se a diferença de comportamento desses materiais celulósicos no solo.

Analisando-se as constantes de velocidade de decomposição dos materiais nota-se que a palha de cana se decompõe praticamente três vezes mais rapidamente que o bagaço. Entretanto, considerando-se a liberação de $\mathrm{CO}_{2}$, nota-se que a quantidade fornecida pela palha foi mais que o dobro daquela produzida pelo bagaço.

Esses resultados permitem que se tenha um perfeito entendimento do significado dos parâmetros cinéticos na avaliação da degradação dos compostos orgânicos: uma pequena fração do carbono orgânico da palha $(18,2 \%)$ é degradada rapidamente, enquanto que, através de um processo três vezes mais lento, degrada-se $43,4 \%$ do carbono orgânico do bagaço. Em outras palavras, a grandeza da constante de velocidade evidentemente não indica a extensão que pode-se atingir na degradação do material orgânico.

Praticamente não se verificou efeito da decomposição dos compostos orgânicos sobre o $\mathrm{pH}$ do solo neste experimento, pois apenas o bagaço de cana proporcionou um ligeiro aumento no $\mathrm{pH}$ do solo. Esses resultados contrastam com o que foi observado no experimento 2 .

Deve-se ressaltar que freqüentemente o efeito de materiais orgânicos sobre $\mathrm{opH}$ do solo pode ser temporário e que a tendência do solo é retornar à condição original. Tal observação pode ser justificada pela diferença entre o tempo de incubação dos experimentos 2 e 3 . 


\section{Palha de Cana e Bagaço de Cana}

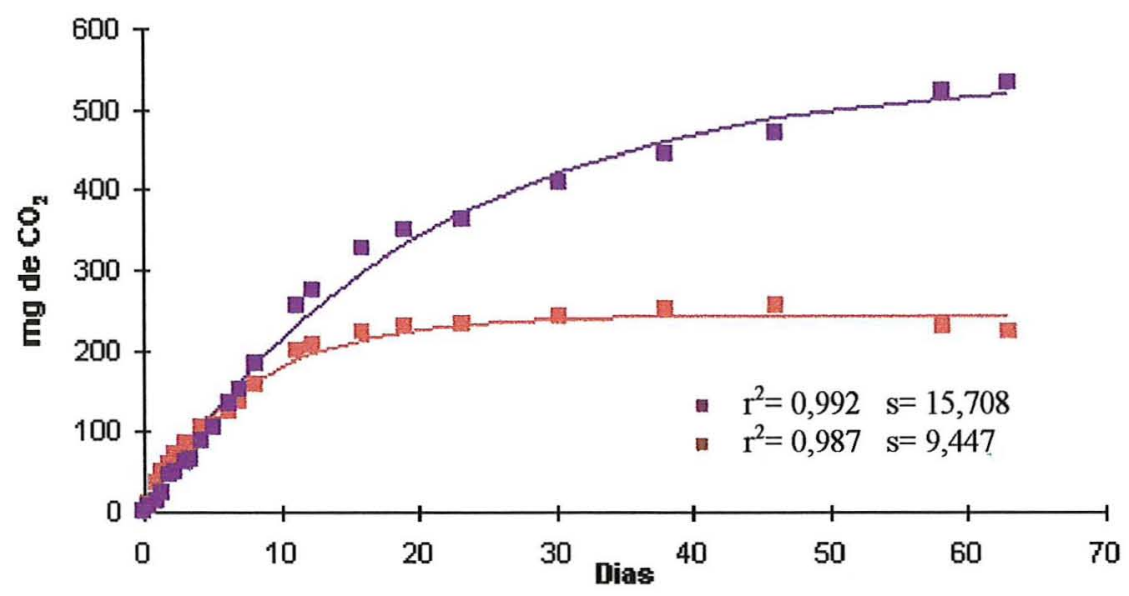

Figura 11-Quantidade acumulada de $\mathrm{CO}_{2}$ liberado do solo em função do tempo de incubação dos compostos orgânicos indicados: pontos experimentais e curva ajustada ao modelo de cinética de primeira ordem. Indicação dos coeficientes de determinação $\left(\mathrm{r}^{2}\right)$ e dos desvios padrão (s).

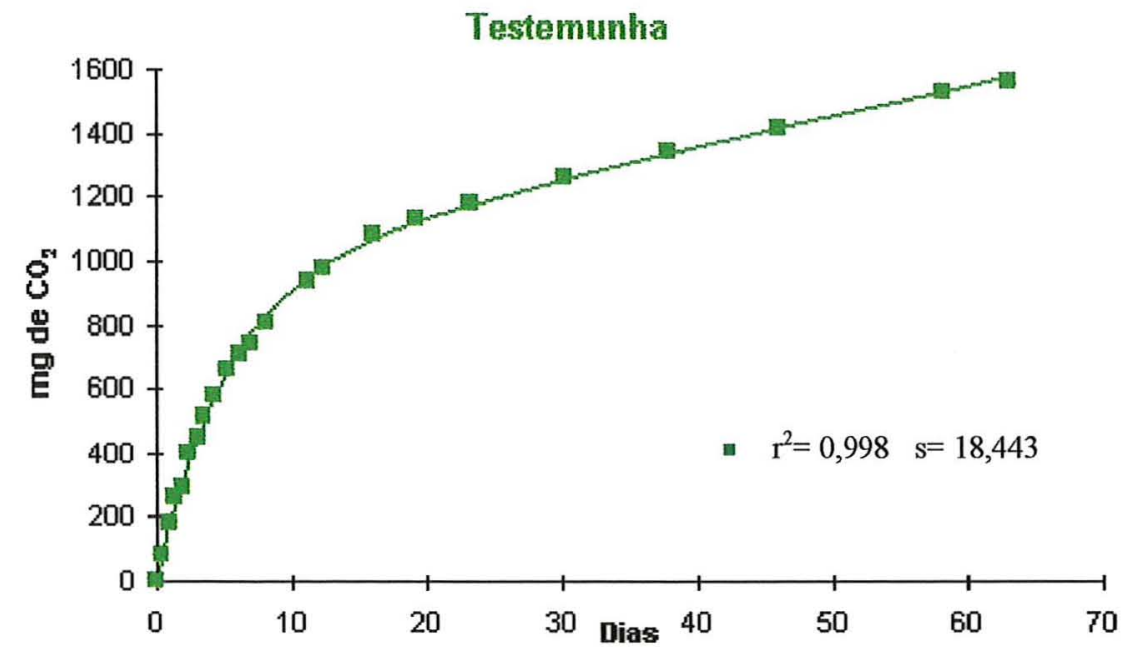

Figura 12-Quantidade acumulada de $\mathrm{CO}_{2}$ liberado do solo em função do tempo de incubação dos compostos orgânicos indicados: pontos experimentais e curva ajustada ao modelo de cinética de primeira ordem. Indicação do coeficiente de determinação $\left(\mathrm{r}^{2}\right)$ e do desvio padrão (s). 


\subsection{Experimento 4. Decomposição de resíduos orgânicos no solo}

Nos experimentos anteriormente discutidos a produção de $\mathrm{CO}_{2}$ dos tratamentos incubados com material orgânico foi obtida descontando-se a contribuição da testemunha. No experimento com incubação de resíduos esse procedimento se mostrou inadequado, pois os dados experimentais parecem indicar que a liberação de $\mathrm{CO}_{2}$ do solo, na presença dos resíduos, se deu com velocidade menor daquela ocorrida durante a incubação do solo natural. Esta hipótese foi levantada, pois a quantidade líquida de $\mathrm{CO}_{2}$ acumulada ao final do período de incubação, ao invés de se estabilizar começou a decrescer, conforme pode ser observado nas Figuras 13, 14 e 15. Esse decréscimo não poderia ocorrer, admitindo-se que o processo de degradação do carbono orgânico do solo seja idêntico, tanto na condição natural como sob incorporação dos resíduos.

Quando um material orgânico está se degradando, a curva de $\mathrm{CO}_{2}$ acumulado é ascendente e, caso a decomposição do material cesse, a curva passará a refletir apenas o comportamento do solo natural e ficará então paralela ao eixo das abcissas.

Esse comportamento diferenciado do solo na presença e na ausência dos resíduos orgânicos pode ter ocorrido durante todo o período de incubação, mas, no início, quando a produção de $\mathrm{CO}_{2}$ pelo material orgânico incubado era mais intensa, isto provavelmente não pudesse ser evidenciado.

Tudo indica que esses resultados sejam decorrentes de um efeito negativo da incorporação dos resíduos, parecendo ter havido uma inibição da decomposição do carbono orgânico nativo do solo. Esse fato ocorreu com os 
dados fornecidos pelos três resíduos orgânicos estudados, sendo mais acentuado com o resíduo de café.

Em vista do exposto anteriormente, optou-se por considerar a cinética de degradação do carbono orgânico dos resíduos e do solo em conjunto. Para essa finalidade, empregou-se o modelo que considera duas frações diferenciadas quanto à velocidade de decomposição.

Desta forma, na Figuras 16 são mostradas as curvas de produção acumulada de $\mathrm{CO}_{2}$ para a testemunha, o resíduo de café solúvel, a vinhaça e o lodo de esgoto, com os pontos experimentais e a curva ajustada. Observase através dos $r^{2}$ que o modelo cinético adotado se ajustou perfeitamente em todas as situações.

Os parâmetros do citado modelo são apresentados na Tabela 9 e neste caso não foi possível incluir o cálculo da fração de carbono orgânico decomposto dos materiais, tendo em vista que os dados se referem à decomposição conjunta do carbono orgânico do solo e dos resíduos orgânicos incubados.

É interessante ressaltar que a grandeza das constantes de velocidade da primeira fase, $\mathrm{k}_{1}$, referentes à testemunha e aos materiais orgânicos, não diferiram apreciavelmente entre si. Isso indica apenas que na primeira fase, com possível exceção do lodo de esgoto, os materiais orgânicos degradaram-se com velocidade similar a do carbono orgânico nativo do solo.

Quanto às constantes de velocidade da segunda fase, estas não fornecem um maior esclarecimento na comparação do comportamento dos materiais orgânicos no solo. 
Resíduo de Café

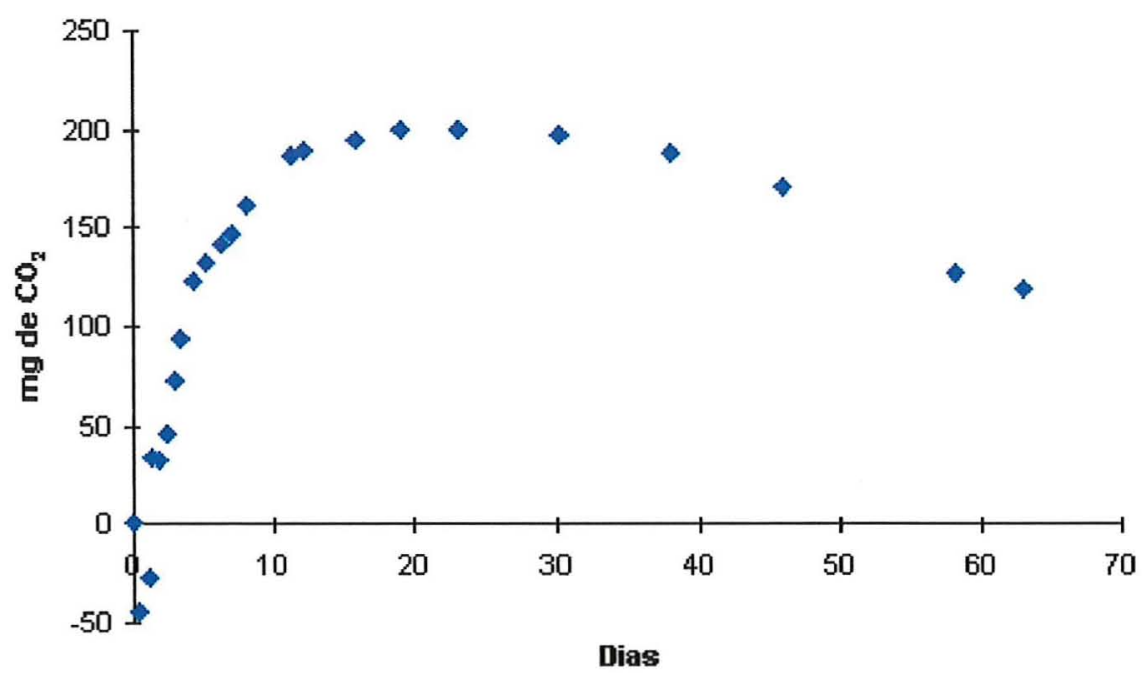

Figura 13-Quantidade acumulada de $\mathrm{CO}_{2}$ liberado do solo, descontando-se a testemunha, em função do tempo de incubação: pontos experimentais.

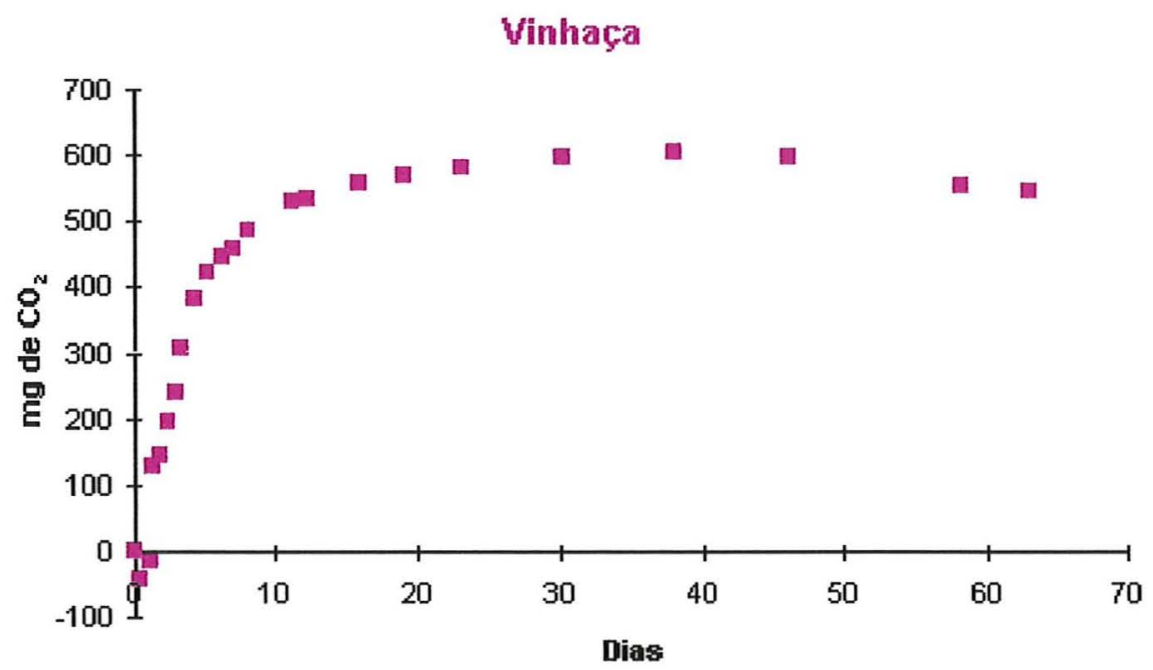

Figura 14-Quantidade acumulada de $\mathrm{CO}_{2}$ liberado do solo, descontando-se a testemunha, em função do tempo de incubação: pontos experimentais. 


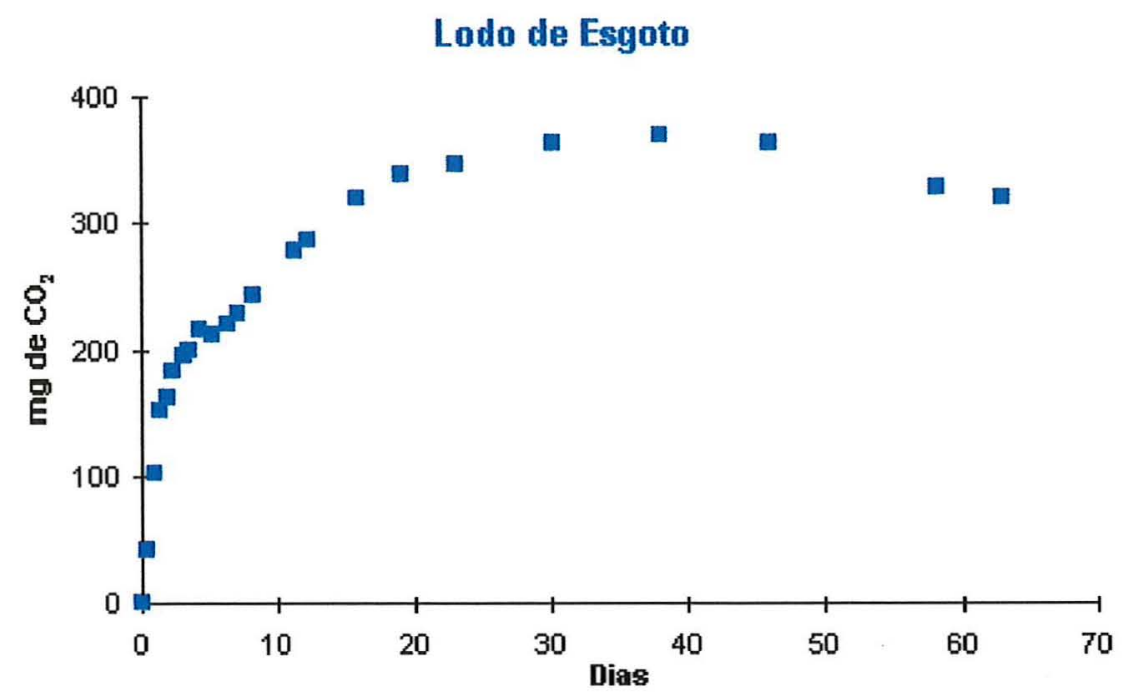

Figura 15-Quantidade acumulada de $\mathrm{CO}_{2}$ liberado do solo, descontando-se a testemunha, em função do tempo de incubação: pontos experimentais.

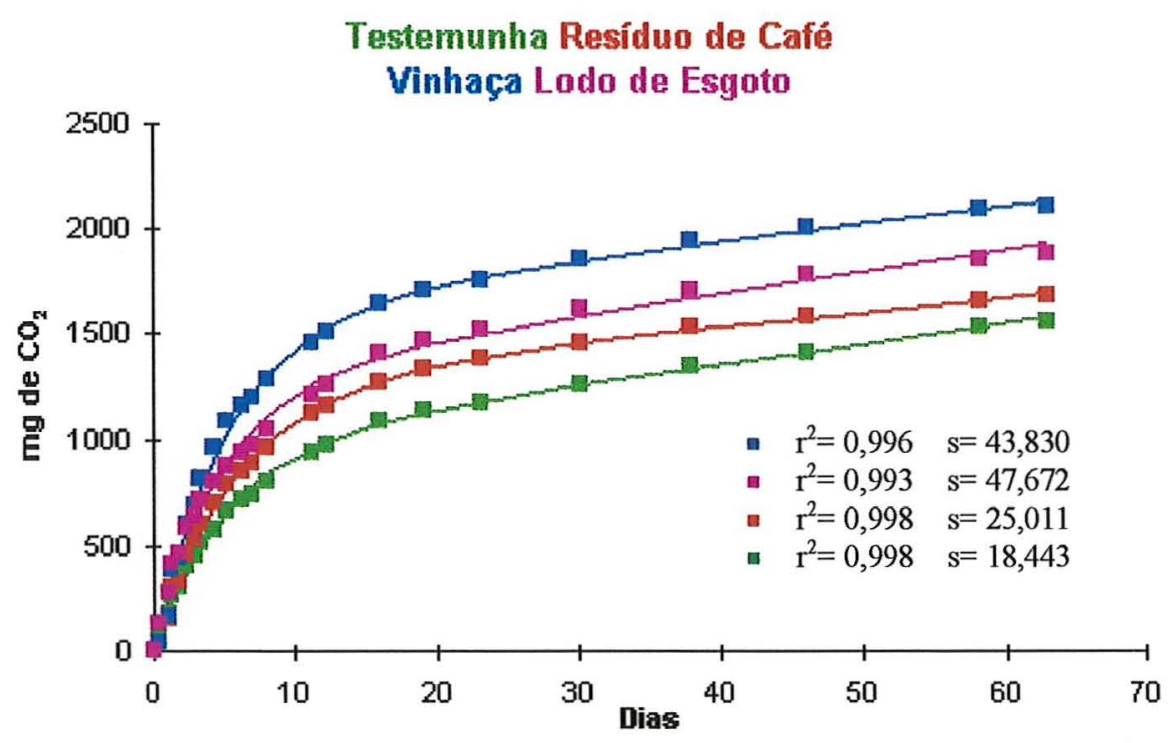

Figura 16-Quantidade acumulada de $\mathrm{CO}_{2}$ liberado do solo em função do tempo de incubação dos compostos orgânicos indicados: pontos experimentais e curva ajustada ao modelo de cinética de primeira ordem. Indicação dos coeficientes de determinação $\left(\mathrm{r}^{2}\right)$ e dos desvios padrão (s). 


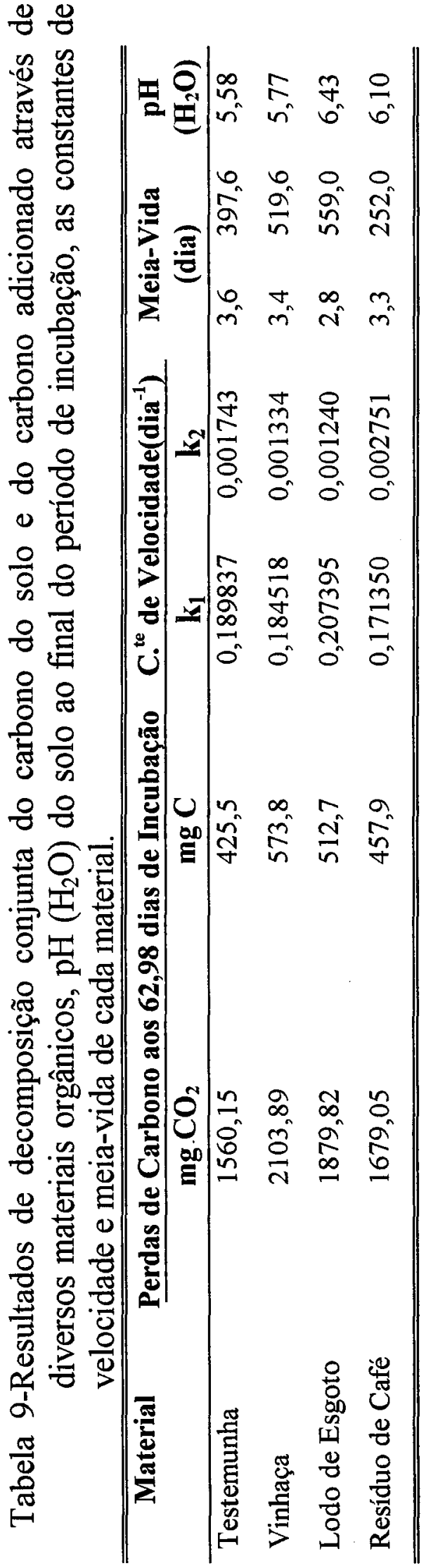


Pela produção total de $\mathrm{CO}_{2}$ obtida é possível constatar que a vinhaça promoveu a maior liberação de $\mathrm{CO}_{2}$, seguindo-se o lodo de esgoto, o resíduo de café solúvel e a testemunha.

Essa ordem está de acordo com as características químicas dos mencionados materiais. Os compostos orgânicos da vinhaça incluem glicerina e ácidos orgânicos solúveis, de degradação relativamente fácil no solo, o que já provavelmente não ocorre com o resíduo de café solúvel, cuja fração orgânica é constituída por compostos fenólicos.

$\mathrm{O} \mathrm{pH}$ do solo ao final do experimento foi mais elevado em decorrência da incubação dos resíduos orgânicos. O lodo de esgoto, material mais alcalino promoveu alteração mais acentuada no $\mathrm{pH}$ do solo. 


\section{CONCLUSÕES}

Considerando-se as condições nas quais se desenvolveu o presente estudo, os resultados permitem estabelecer as seguintes conclusões sobre a decomposição de compostos orgânicos em um Latossolo Vermelho Amarelo, fase arenosa:

-O modelo de cinética de primeira ordem foi adequado para interpretar a decomposição de compostos orgânicos incubados.

-A ordem decrescente de velocidade de decomposição para os materiais estudados foi: sacarose, isolado de proteína de soja, glicerina, pectina, ácido cítrico, amido, tanino, celulose, óleo de soja, ágar, ácido húmico e lignina.

-Os parâmetros cinéticos do modelo de primeira ordem caracterizaram a influência da temperatura no processo de decomposição. A sacarose foi o composto orgânico que se decompôs mais rapidamente, seguida pelo tanino e pectina.

-O modelo de cinética de primeira ordem em duas fases, foi eficiente para interpretar a degradação dos diferentes compostos orgânicos misturados.

-A incubação de resíduos orgânicos industriais e urbanos afeta a degradação da matéria orgânica nativa do solo. Analisando a produção total 
de $\mathrm{CO}_{2}$, a vinhaça promoveu maior liberação de $\mathrm{CO}_{2}$, seguindo-se o lodo de esgoto e o resíduo de fabricação de café solúvel. 


\section{REFERÊNCIAS BIBLIOGRÁFICAS}

ALEXANDER, M.; SCOW, M. Kinetics of biodegradation in soil In: SAWHNEY, B.L.; BROWN, K. (Ed.). Reactions and movement of organic chemicals in soils Madison: Soil Science Society of America; American Society of Agronomy, 1989. cap 10, p. 243-269.

ALEXANDER, M. I. H. Introduction to soil microbiology. 4.ed. New York: John Wiley, 1967. 472 p.

ALMEIDA, M. T. Decomposição vinhaça adicionada ao solo (evolução de $\mathrm{CO}_{2}$ e formação de biomassa microbiana ) e destino da complementação nitrogenada. Piracicaba, 1983. 75 p. Dissertação (Mestrado) - Escola Superior de Agricultura "Luiz de Queiroz", Universidade de São Paulo.

BRADY, N. C. Natureza e propriedades dos solos. 7.ed. Rio de Janeiro: Freitas Bastos, 1989. 878 p.

BRUNNER, W.; FOCHT, D. D. Deterministic three-half-order kinetic model for microbial degradation of added carbon substrates in soil. Applied and Environmental Microbiology,v. 47, n.1 p. 167-172, 1984. 
CARDOSO, E. J. B. N.; TSAI, S. M.; NEVES, M. C. P. Microbiologia do solo. Campinas: Sociedade Brasileira de Ciência do Solo, 1992. 360 p.

CERRI, C.C.; JENKINSON, D. S. Formation of microbial biomass during the decomposition of ${ }^{14} \mathrm{C}$ labelled ryegrass in soil. Journal of Soil Science, v. 32, n. 4 p. 619-626, 1981.

DUMONTET, S.; PARENTE, E.; COPPOLA, S. Mineralization of organic matter in soil treated with sewage sludge stablized by different methods. In: WLLIÂMS, J.H. (Ed.), Long term effects of sewage sludge and farm sluvies applications. Elsevier: 1985. p.177-189.

EIRA, A.F.; PACCOLA, A.A. Eficiência de inoculantes para compostagem da torta de filtro rotativo. Brasil Açucareiro, v.96, n.6, p.52-61, 1980.

EVANS, J.O. Soil as sludge assimilators. Compost Science, v. 14, n. 6, p. 16-21,1973.

JENKINSON D.S.; RAYNER, J.H. The turnover of soil organic matter in some of the Rothamsted Classical Experiments. Soil Science, v. 123, p.298-305, 1977.

KIEHL , E. J. Matéria orgânica. In: Apostilas dos trabalhos da semana sobre matéria orgânica. Piracicaba: s.ed., 1981. p.1-12. 
KIEHL, E. J. Fertilizantes orgânicos. Piracicaba: Ceres, 1985. 492 p.

LATHAN, J.L. Cinética elementar de reação. São Paulo: Egard Blucher; EDUSP, 1974. 113p.

MARTINS, D. Influência do $\mathrm{CO}_{2}$ proveniente da decomposição de material vegetal incorporado ao solo nas razões isotópicas ${ }^{13} \mathrm{C} /{ }^{12} \mathrm{C}$ e desenvolvimento das plantas. Piracicaba, 1987. 132 p. Tese (Doutorado) - Escola Superior de Agricultura "Luiz de Queiroz", Universidade de São Paulo.

MEITES, L. The general multiparametric curve fitting program CFT4. Postdam: Clarkson College of Tecnology, Departament of Chemistry, Computing Laboratory, 1976. 206 p.

MINHONI, M. T. A.; CERRI, C. C. Decomposição de vinhaça em solos sob diferentes níveis de umidade: liberação $\mathrm{deCO}_{2}$,formação de biomassa microbiana e imobilização do nitrogênio adicionado. Revista Brasileira de Ciência do Solo, v.11, p.25-30, 1987.

MINHONI, M. T. A.; EIRA, A. F. ; CARDOSO, E. J. B. N. Efeitos de N e P sobre a decomposição de diferentes tipos de material orgânico no solo. Revista Brasileira de Ciência do Solo, v.14, p.297-304, 1990. 
MORRILL, L. G.; MAHILUM, B. C.; MOHIUDDIN, S. H. Organics compounds in soils: sorption, degradation and persistance. Ann Arbor Science, 1982.157p.

PARR, J.F. Chemical and biological considerations for land application of agricultural land municipal wastes In: FAO. Organic materials as fertilizers. Rome, 1975. p.227-251 (FAO. Soils Bulletin,27).

PAUL, D. ; BROADBENT, F. E. Kinetics of rice straw decomposition in soils. Journal of Environmental Quality, v. 4, n. 2, p. 256-260, 1975.

PAUL, E. A. Dinamics of organic matter in soil. Plant and Soil, v. 76, p.275$285,1984$.

PONNAMPERUMA, F. N. The chemistry of submerged soils. Advances in Agronomy, v. 24, p. 29-96, 1972.

REDDY, K. R.; FEISTEL, T. C. PATRICK JR, W. H. Effect of soil redox conditions on microbial oxidation of organic matter. In: CHEN, Y.; AVNIMELECH, Y. (Ed.). The role of organic matter in modern agriculture. Dordrecht: Martinus Nijhoff. 1986. cap 6 p, 117-156. 
REDDY, K. R.; KHALEEL, R.; OVERCASH, M. R. Carbon transformations in the land areas receiving organic wasres in reation to nonpoint source pollution: a conceptual model. Journal of Environmental Quality, n.9, v.3, 434-442 p. 1980.

RODELLA, A. A. Métodos de avaliação de materiais orgânicos e efeitos de sua incorporação ao solo sobre a mobilização de macronutrientes. Piracicaba, 1996. 148 p. Tese (Livre Docência)- Escola Superior de Agricultura "Luiz de Queiroz", Universidade de São Paulo.

RODELLA, A. A; ALCARDE, J.C. Avaliação de materiais orgânicos empregados como fertilizantes. Scientia Agricola , v.51, n.3, p. 556-562, 1994.

RODELLA, A.A.; ZAMBELLO JUNIOR, E.; ORLANDO FILHO, J. Effects of vinasse added to soil on $\mathrm{pH}$ and exchangeable aluminium content. In: CONGRESS OF THE International Society of Sugar Cane Tecnologists, 18., Cuba, 1983. Proceedings. Cuba: ISSCT, 1983. v.1, p. 237-247.

SABOYA, L. V.; RODELLA, A. A Emprego de método condutimétrico em respirometria de solo. In: SIMPÓSIO DE INICIAÇÃO CIENTÍFICA DA USP, 3., Piracicaba , 1995. Anais. Piracicaba: ESALQ, 1995. v.1. p.364. 
SINGH, J. S.; GUPTA, S. R. Plant Decomposition and Soil Respiration in Terrestrial Ecossystems. The Botanical Review, v.43, n.4, p. 449-528, 1977.

SIQUEIRA, J. O. Biotecnologia do solo: fundamentos e perspectivas. Brasília MEC, ESAL, Potafos,1983. 263 p.

SMOLANDER, A; KITUNEN, V. PAAVOLANINEN, L. MALKONEN, E. Decomposition of Norway spruce and Scots Pine Needles: Effects of liming. Plant and Soil, v. 179, n.1, p.1-7, 1996.

SOUZA, M. R. Tecnologias para usos alternativos de resíduos florestais: experiências do laboratório de produtos florestais -IBAMA, na área de utilização de resíduos florestais e agrícolas. In: WORKSHOP SULAMERICANO SOBRE USOS ALTERNATIVOS DE RESÍDUOS DE ORIGEM FLORESTAL E URBANA, Curitiba, 1997. Anais. p.49.

STECHER, P.G.(Ed), The merck index chemical monographs and drugs. Rahway: Merck \& Co, 1960. 1642 p.

STROO, H. F.; BRISTOW, K. L.; ELLIOT, L. F., PAPENDICK, R. I. and CAMPBELL,G.S. Predicting rates of wheat residue decomposition. Soil Science Society of America Journal, v. 53, n.1, p.91-99. 1989. 
TERRY, R.E.;NELSON, D.W.; SOMMERS, E. Carbon cycling during sewage sludge decomposition in soils. Soil Science Society of America Journal, v. 43, p. 494-499, 1979.

VANLAUWE, B., DENDOOVEN, L.;MERCKY, R. Residue and fractionation decomposition: The significance of the active fraction. Plant and Soil, v.158, p.263-274, 1994.

WAKSMAN, S.A Soil microbiology. 4. ed. New York: John Wiley, 1963. $356 \mathrm{p}$. 